\title{
Study on the Mechanism and Control of Rock Burst of Coal Pillar under Complex Conditions
}

\author{
Xingping Lai $\left(\mathbb{D},{ }^{1,2}\right.$ Huicong Xu $\mathbb{D},{ }^{1,2}$ Jingdao Fan, ${ }^{1,3}$ Zeyang Wang, ${ }^{4}$ Zhenguo Yan, \\ Pengfei Shan $\mathbb{D}^{1,2}$ Jie Ren, ${ }^{1,2}$ Shuai Zhang, ${ }^{1,2}$ and Yanbin Yang ${ }^{1,2}$ \\ ${ }^{1}$ State Key Laboratory of Coal Resources in Western China, Xi'an 710054, China \\ ${ }^{2}$ School of Energy Engineering, Xi'an University of Science and Technology, Xi'an 710054, China \\ ${ }^{3}$ Shaanxi Yanchang Petroleum (Group) Co., Ltd., Xi'an 710075, China \\ ${ }^{4}$ China Coal Technology \& Engineering Group Xi'an Research Institute, Xi'an 710054, China \\ ${ }^{5}$ College of Safety Science and Engineering, Xi'an University of the Science and Technology, Xi'an 710054, China
}

Correspondence should be addressed to Huicong Xu; xhcxust@163.com and Pengfei Shan; shanpengfei@xust.edu.cn

Received 22 May 2020; Revised 22 September 2020; Accepted 29 September 2020; Published 28 October 2020

Academic Editor: Zongqing Zhou

Copyright (c) 2020 Xingping Lai et al. This is an open access article distributed under the Creative Commons Attribution License, which permits unrestricted use, distribution, and reproduction in any medium, provided the original work is properly cited.

In order to explore the mechanism of coal pillar rock burst in the overlying coal body area, taking W1123 working face of Kuangou Coal Mine as the engineering background, the full mining stage of W1123 is simulated by FLAC ${ }^{3 \mathrm{D}}$. It is found that the high stress concentration area has appeared on both sides of the coal pillar when W1123 does not start mining. With the advance of the working face, the high stress concentration area forms X-shaped overlap. There is an obvious difference in the stress state between the coal pillar under the solid coal and the coal pillar under the gob in W1123. The concrete manifestation is that the vertical stress of the coal pillar below the solid coal is greater than the vertical stress of the coal pillar below the gob. The position of the obvious increase of the stress of the coal pillar in the lower part of the solid coal is ahead of the advancing position of the working face, and the position of the obvious increase of the stress of the lower coal pillar in the gob lags behind the advancing position of the working face. At the same time, in order to accurately reflect the true stress environment of coal pillars, the author conducted a physical similarity simulation experiment in the laboratory to study the local mining process of the W1123 working face, and it is found that under the condition of extremely thick and hard roof, the roof will be formed in the gob, the mechanical model of roof hinged structurer is constructed and analyzed, and the results show that the horizontal thrust of roof structure increases with the increase of rotation angle. With the development of mining activities, the self-stable state of the high stress balance in the coal pillar is easily broken by the impact energy formed by the sudden collapse of the key strata. Therefore, the rock burst of coal pillar in the overlying coal body area is the result of both static load and dynamic load. In view of the actual situation of the Kuangou Coal Mine, the treatment measures of rock burst are put forward from the point of view of the coal body and rock mass.

\section{Introduction}

Rock burst is a common phenomenon of rock dynamic failure in the process of coal mining, which is characterized by a large deformation of rock mass, throwing out rock blocks, producing a loud sound, ejecting gas waves, and so on $[1,2]$. Rock burst is studied through various methods such as rock mechanics experiments, numerical calculations, and theoretical analysis. It is generally believed that the cause of rock burst is the accumulation of large amounts of elastic energy in the rock mass, and when the accumulation of elastic energy reaches the load limit of the rock mass, it will instantly release elastic energy [3-9].

In the field of rock burst generation mechanism. Lai et al. pointed out that the occurrence of steeply inclined rock burst is caused by the prying effect of rock pillar between coal seams after it enters the depth with mining $[10,11]$. 
Pan et al. put forward that the intrinsic factor of rockburst start-up is the excessive accumulation of static load in the near-field system of mining rock; the possible areas of rockburst start-up are the maximum peak areas of stress in the region of limit equilibrium [12]. Gong et al. improved the prediction accuracy of rock burst by adaptive-grid method and passive seismic tomography [13]. Zhu et al. investigated the influence of overstress state on rockburst in deep underground coal mining and found that compared to triaxial loading, coal samples are more easy to deform and bring to failure under triaxial unloading [14]. For Dai et al., the rock physical and mechanical parameters of 36 near horizontal coal seams are collected and the prediction model of coal pillar width is constructed $[15,16]$.

Scholars at home and abroad have studied rockburst from the relatively independent aspects of rockburst mechanism, unloading, and prevention technology. However, the difference of stress distribution below the overlying coal body is rarely taken into account.

This paper considers that due to the sudden thinning of coal seam in the W1145 working face of Kuangou Coal Mine, it is impossible to use existing equipment for mining, so a large number of coal body are left, which has an impact on the mining of W1143 working face which is below gob W1145. Though the rock burst is caused by the dynamic and static binding load mechanisms, the numerical simulation method is used to study the internal stress distribution characteristics of a coal pillar in different environments of overlying coal body area and overlying gob area. The mechanical model of the roof is constructed and analyzed, and the results show that the horizontal thrust of the roof structure increases with the increase of the rotation angle. The engineering treatment of the coal and rock mass is carried out from two aspects of structure and energy. The treatment effect is evaluated microseismic monitoring; microseismic data show that blasting and large-diameter boreholes can effectively reduce the accumulated elastic properties in the rock, which can provide guarantee for the safety of the personnel and property.

\section{General Engineering Situation}

2.1. Geology of W1123 Working Face. The Kuangou Mine is under the jurisdiction of Shenxin Company. The administrative division is under the jurisdiction of Queergou Town, Hutubi County, Changji Prefecture, Xinjiang. The coal mine is located in Shawan County-Manas County-Hutubi County earthquake belt.

The coal mine main mining coal seam no. B4-1 and coal seam no. B2 are gently inclined coal seams. The average thickness of coal seam no. B4-1 is $3 \mathrm{~m}$, and the two working faces are arranged in W1143 and W1145, in which the total length of the W1143 face is $164 \mathrm{~m}$ and the total length of the W1145 face is $175 \mathrm{~m}$. The average thickness of the B2 coal seam is $9.5 \mathrm{~m}$, and the two working faces are W1121 and W1123, respectively.

The total length of W1121 is $149 \mathrm{~m}$, and the total length of W1123 is $192 \mathrm{~m}$. The average vertical distance between coal seam no. B4-1 and coal seam no. B2 is about $427.9 \mathrm{~m}$, the thickness of bedrock is $421 \mathrm{~m}$, the thickness of loose soil is $15.9 \mathrm{~m}$, and the buried depth is about $427.9 \mathrm{~m}$. The $15.9 \mathrm{~m}$ thick coarse-grained sandstone at $21.9 \mathrm{~m}$ above the B4-l coal seam is the main key layer of the overlying rock, and the $14 \mathrm{~m}$ thick coarse-grained sandstone at $21.8 \mathrm{~m}$ above coal seam no. B2 is the subkey layer of the overlying rock, and the mine coal seam belongs to the group of deep-buried coal seams at close distance. Longwall fully mechanized top coal caving is adopted.

Due to the sudden thinning of coal seam no. B4-1, mechanized coal mining cannot be continued, so the remaining coal seam has not been mined. The strike length of W1145 is about $480 \mathrm{~m}$ and that of W1123 is about $1000 \mathrm{~m}$. There will be two stages during the mining period of the W1123 working face. At the beginning of W1123, the open cut is under the thinning area of coal seam no.4-1; after mining about $400 \mathrm{~m}$, the working face will be under gob W1145.The structural diagram of the Kuangou Coal Mine is shown in Figure 1.

\subsection{Characteristics of Microseismic Distribution. Microseis-} mic monitoring technology, which is based on acoustic emission and seismology, has developed into a new type of hightech monitoring technology. It is a geophysical technology to monitor the influence, effect, and underground state of production activities by observing and analyzing small seismic events in production activities. When the underground rock breaks and moves due to manmade or natural factors, a weak seismic wave propagates around. By arranging several groups of geophones in the space around the fracture zone and collecting microseismic data in real time, after data processing, using the principle of vibration location, the location of the rupture can be determined and displayed in a threedimensional space.

A rockburst event occurred 60 meters in front of the working face during the mining period of W1123 on March 7, 2018. During the mining of the working face, the coal mine uses the microseismic monitoring system to monitor and locate the microseismic events and energy of the working face. Through the analysis of microseismic records, the energy value is $3.1 \times 10^{5} \mathrm{~J}$, and the specific position is on the side of the coal pillar in the headgate (Figure 2). The different colored dots in the picture represent the energy magnitude and location of microseismic events.

When the high-energy event occurs, it is accompanied by a loud noise, resulting in a net pocket in the shoulder fossa in the lower section of the leading working face 50$55 \mathrm{~m}$ along the headgate, and the secondary small energy event occurs frequently after the occurrence of the highenergy event.

We analyze events and energy collected by the microseismic equipment in the working face on March 7 and before extracting them as shown in Figure 3. Before the occurrence of rock burst, the total energy and number of microseismic events continue to fluctuate, but three days before the occurrence of shock events, the energy and number of microseismic events begin to increase significantly. 


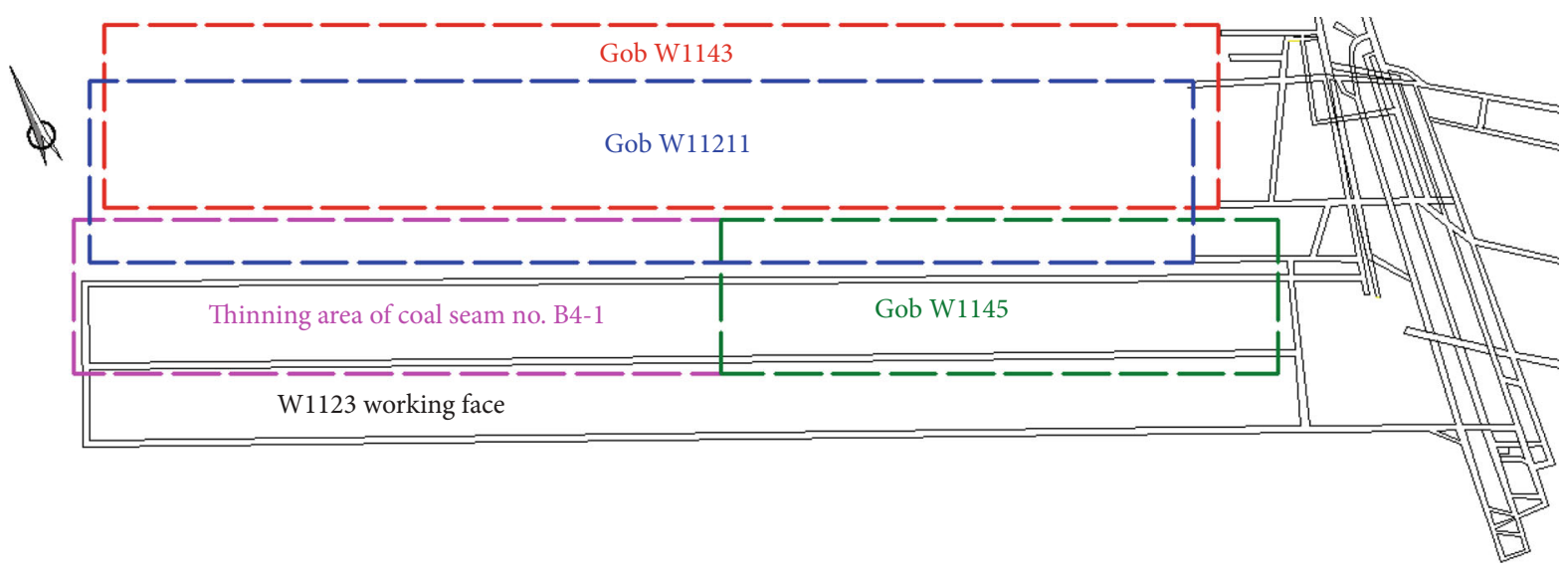

(a)

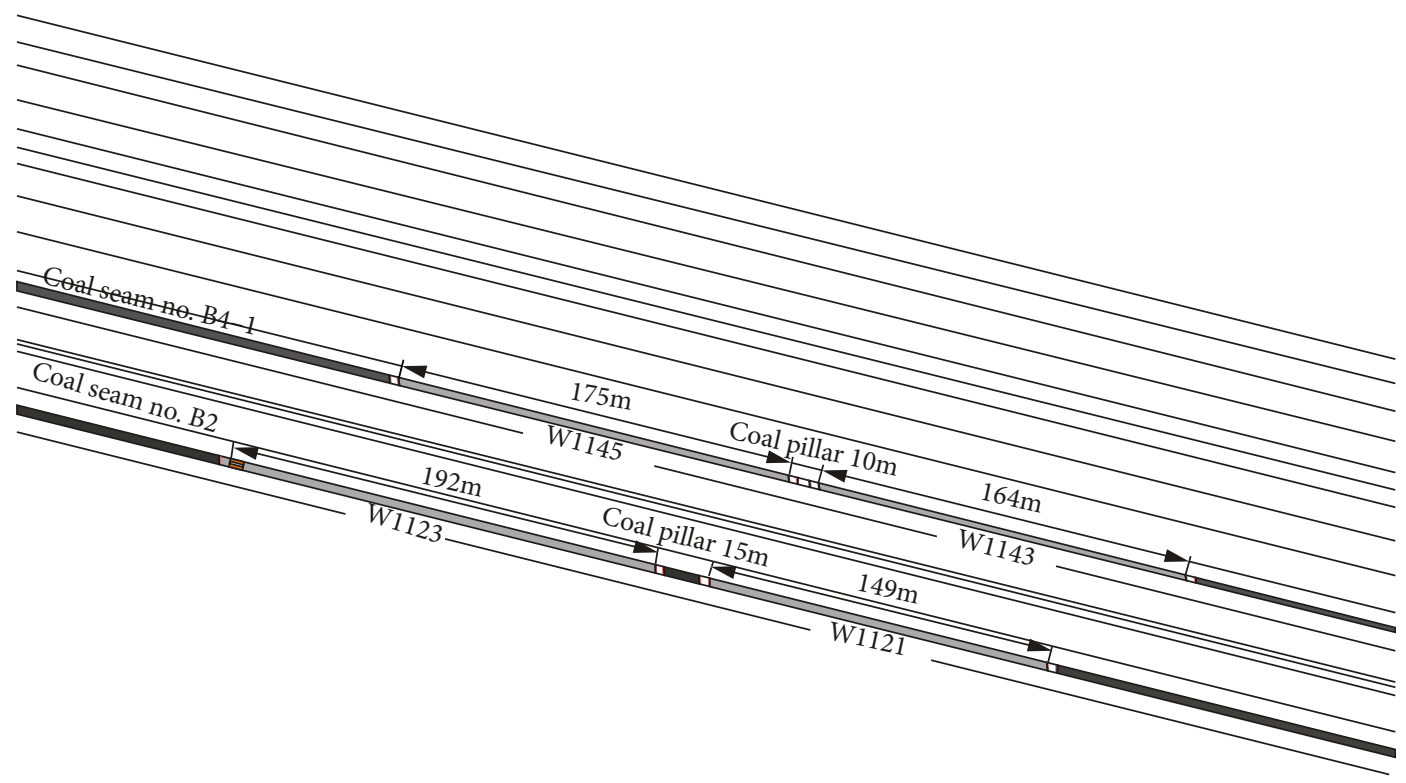

(b)

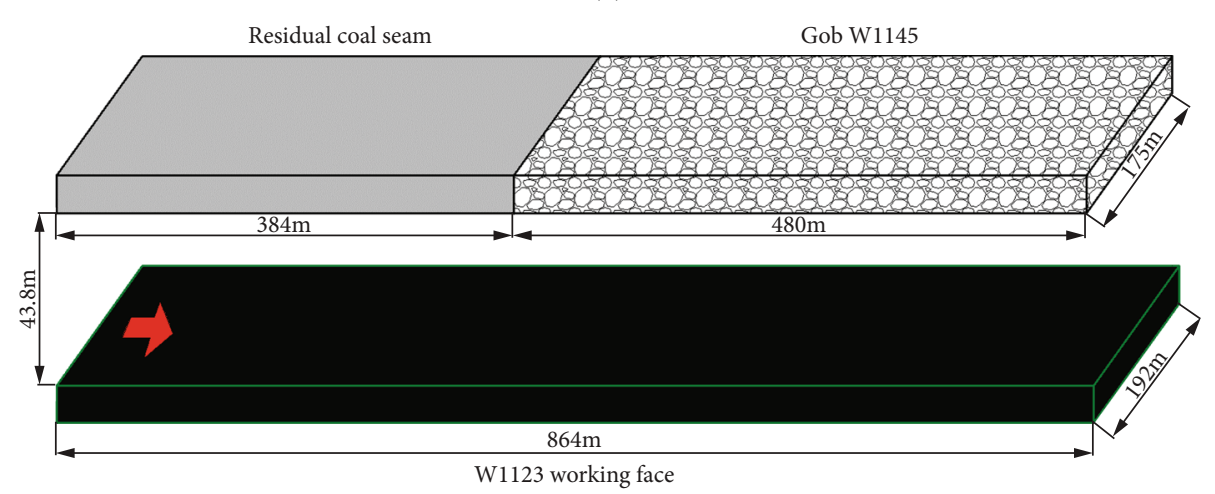

(c)

FIgure 1: Structural diagram of the Kuangou Coal Mine. (a) Plane diagram of the mine. (b) Section diagram of the mine. (c) Schematic diagram of the close-range coal seam.

\section{Evolution Law of Stress Field during the Mining Progress}

3.1. Numerical Simulating Model. Through on-the-spot investigation and analysis, the numerical simulation model of W1123 is established according to the geological column chart and the thickness and inclination of rock strata in the Kuangou Coal Mine. The model size is $420 \mathrm{~m} \times 525 \mathrm{~m} \times$ $326 \mathrm{~m}$ (length $\times$ width $\times$ height), and each roadway size is $4.5 \mathrm{~m} \times 3.5 \mathrm{~m}$ (width $\times$ height) Figure 4 show the threedimensional model established by FLAC $^{3 \mathrm{D}}$ numerical simulation software. 


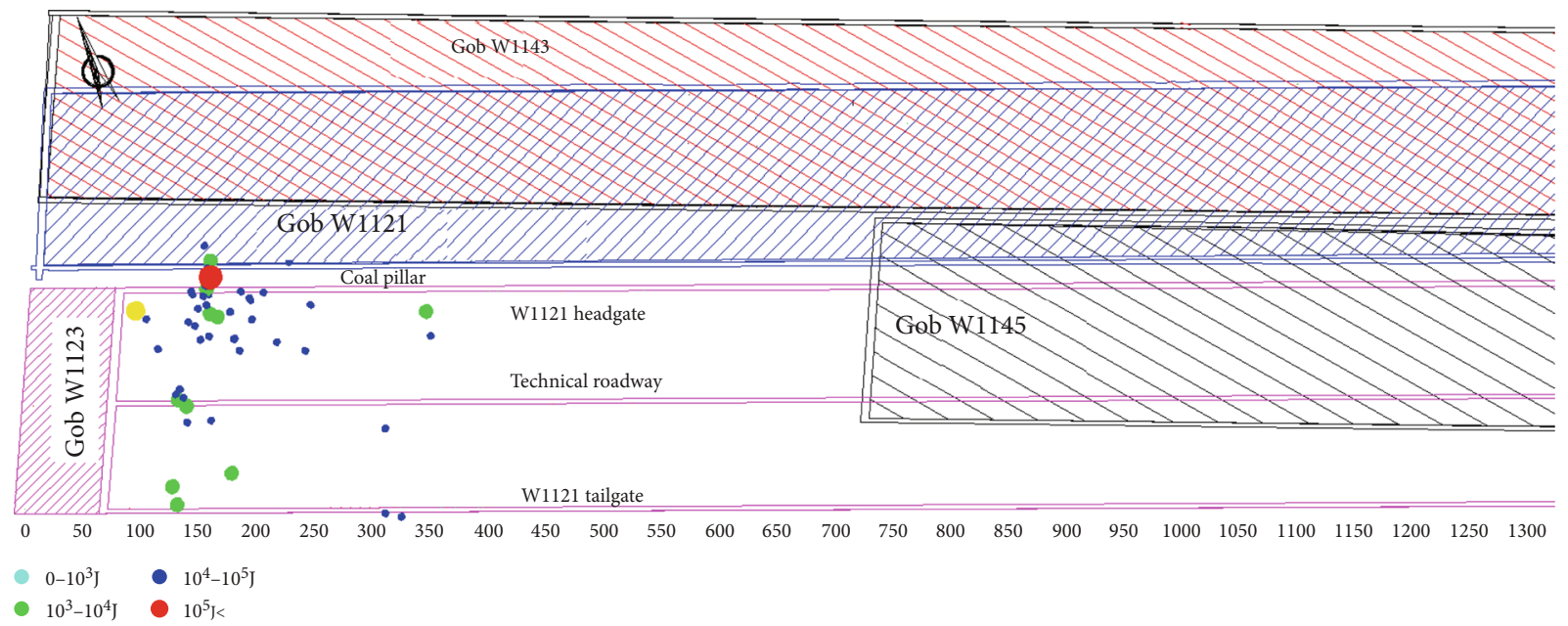

(a)

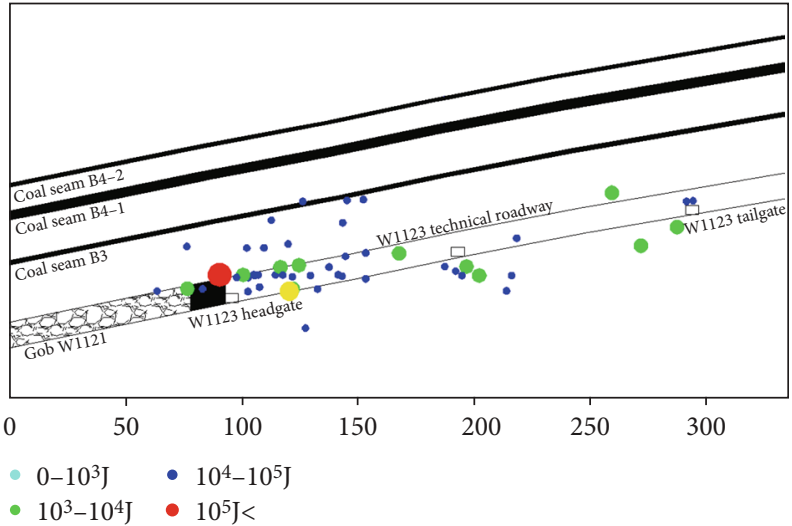

(b)

Figure 2: Microseismic event distribution. (a) Plane diagram. (b) Section diagram.

The numerical simulation model is founded by MohrCoulomb elements, and the gravity is set at $9.8 \mathrm{~m} / \mathrm{s}^{2}$. The horizontal displacement constraint is imposed on both sides of the model, the displacement in the horizontal direction is limited, and the vertical direction is not limited. According to the results of rock stress measurement, as shown in Table 1.After angle conversion, the vertical load of $6.59 \mathrm{MPa}$ is applied on the top of the model, the horizontal load of $11.91 \mathrm{MPa}$ is applied on the front and rear boundaries of the model, the horizontal load of $9.92 \mathrm{MPa}$ is applied on the left and right boundary of the model, and the mechanical parameters of the coal-rock mass are presented in Table 2.

3.2. Stress Distribution Characteristics of the Coal Pillar. Figure 5(a) is the distribution of vertical stress after penetration of the headgate, tailgate, and open-off cut in W1123 which shows that the area of high stress concentration has been shown in the coal pillar when the mining of W1123 has not begun, and the stress in the range of W1123 below the gob is obviously less than that below the solid coal. However, there are obvious zoning characteristics in the high stress area inside the coal pillar: the stress concentration area is widely distributed along the side of the gob of the coal pillar and is distributed in the shape of a point on the side of the gob of W1123. Because of the existence of solid coal in the upper layer, the stress is not released, and with the advance of W1123 working face, the scope of the gob is gradually expanded, and the vertical stress is mainly borne by the gob gangue and coal pillar.

When the model is used to simulate mining, the high stress area inside the coal pillar is distributed at the edge of the coal pillar at first, and the high stress area gradually moves to the middle of the coal pillar as the mining work continues. When the model mining reaches $80 \mathrm{~m}$, the high stress area on both sides of the coal pillar produces Xshaped superposition in the middle of the coal pillar (Figure 5(b)). When the high stress area is superimposed, the three-dimensional spatial distribution of stress field in coal pillar is shown in Figure 6.

We can cognize the characteristics of the zoning inside the coal pillar more figurative: (1) the coal pillar is basically divided into two regions. The first area has a higher overall stress below the upper layer solid coal. The lower overall stress in the second area is below the gob of the upper layer. (2) The stress of the coal pillar increases gradually from outside to inside and finally reaches the peak value on the side of W1123 in the middle of the coal pillar. 


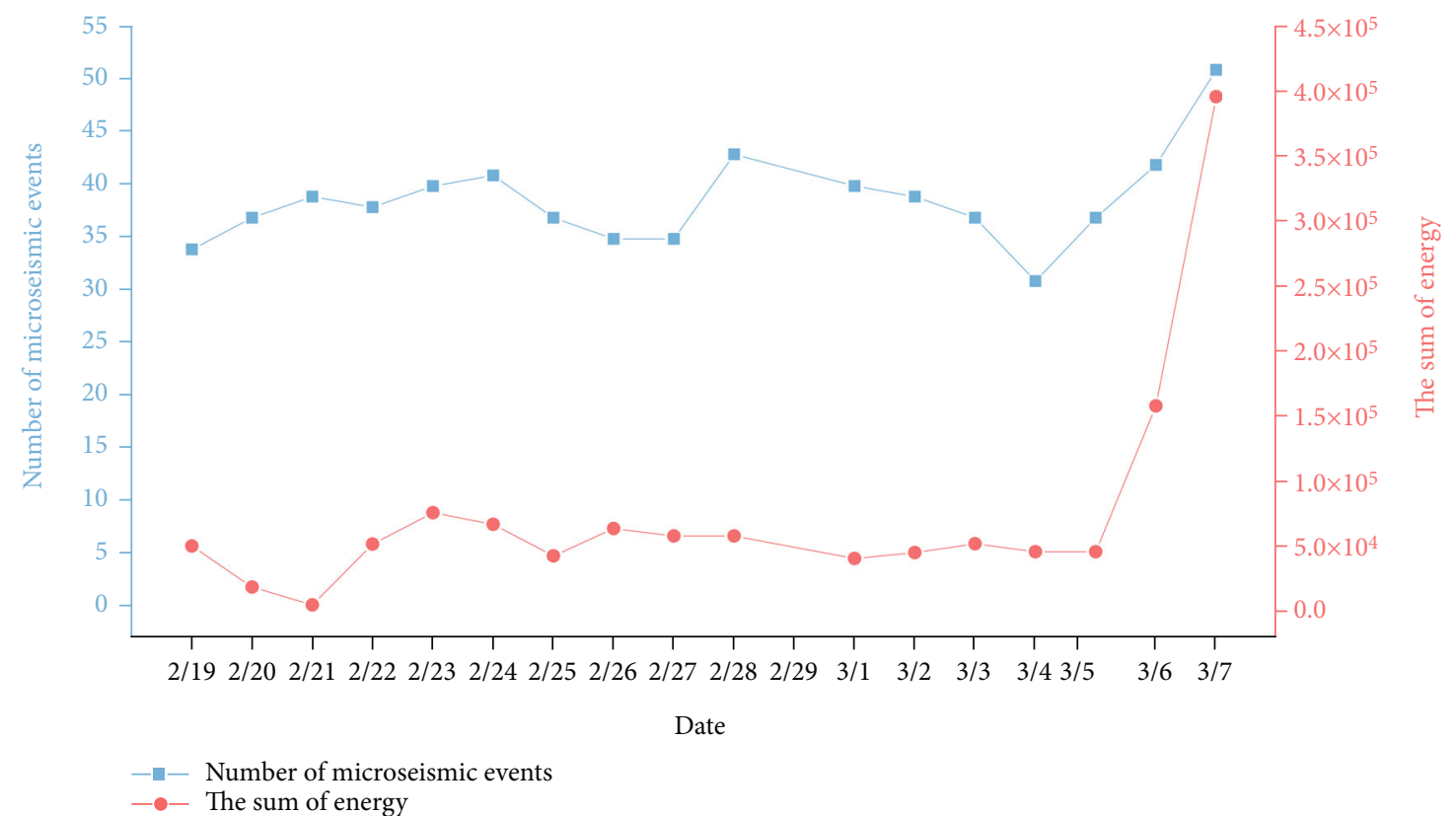

FIgURE 3: Characteristics of microseismic events.

FLAC3D 5.00
@2012 Itasca Consulting Group, Inc.
Zone
Colorby:group any
Coalpillar
Coalseamno.B2
Coalseamno.B3
Coalseamno.B4-1
Coarsesandstone
Mudstone
Packsand
Sandstone
Sandymudstone
W1121
W1121 headgate
W1121 tailgate
W1123
W1123 headgate
W1123 tailgate
W1143
W1145

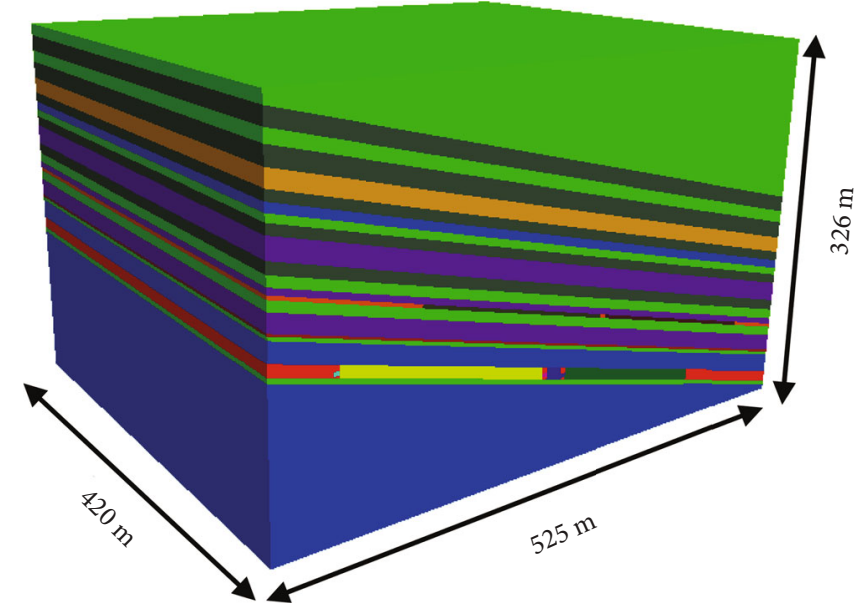

FIgURE 4: Numerical model indication.

TABLE 1: Results of rock stress measurement.

\begin{tabular}{|c|c|c|c|c|c|c|c|c|}
\hline \multicolumn{3}{|c|}{ Maximum principal stress } & \multicolumn{3}{|c|}{ Intermediate principal stress } & \multicolumn{3}{|c|}{ Minimum principal stress } \\
\hline Value $(\mathrm{MPa})$ & Direction $\left({ }^{\circ}\right)$ & Dip angle $\left({ }^{\circ}\right)$ & Value $\left({ }^{\circ}\right)$ & Direction $\left({ }^{\circ}\right)$ & Dip angle $\left({ }^{\circ}\right)$ & Value (MPa) & Direction $\left({ }^{\circ}\right)$ & Dip angle $\left({ }^{\circ}\right)$ \\
\hline 12.8 & 183.1 & -9.9 & 7.5 & 43.6 & -77.0 & 6.8 & 94.5 & 8.3 \\
\hline
\end{tabular}

3.3. Spatial Evolution Law of Stress Field in Coal Pillar. Numerical simulation of the peak stress and peak stress increment of the coal pillar in the process of mining is shown in Figure 7. By comparing the stress peak value and stress peak increment of the coal pillar under different mining progress, it is found that (1) in the mining process of W1123, the peak stress of coal pillar increases from $28.1094 \mathrm{MPa}$ to $55.1590 \mathrm{MPa}$; the growth rate is $96.2 \%$. The process of stress peak growth can be divided into three stages: stable zone, surge zone, and slow increase zone. (2) The peak 
TABLE 2: Physical and mechanical parameters of the coal-rock mass.

\begin{tabular}{|c|c|c|c|c|c|c|c|}
\hline No. & Rock type & $T(\mathrm{~m})$ & $\gamma\left(\mathrm{kg} / \mathrm{m}^{3}\right)$ & $G(\mathrm{GPa})$ & $K(\mathrm{GPa})$ & $C(\mathrm{MPa})$ & $\varphi\left({ }^{\circ}\right)$ \\
\hline 1 & Mudstone & & 2597 & 3.83 & 7.42 & 4.39 & 30.41 \\
\hline 2 & Sandy mudstone & 13.0 & 2546 & 4.41 & 8.12 & 5.42 & 30.41 \\
\hline 3 & Mudstone & 10.0 & 2597 & 3.83 & 7.42 & 4.39 & 30.41 \\
\hline 4 & Sandy mudstone & 14.0 & 2546 & 4.41 & 8.12 & 5.42 & 30.41 \\
\hline 5 & Sandstone & 13.0 & 2467 & 8.5 & 14.17 & 16.22 & 31.74 \\
\hline 6 & Sandy mudstone & 8.0 & 2546 & 4.41 & 8.12 & 5.42 & 30.41 \\
\hline 7 & Packsand & 7.0 & 1304 & 14.07 & 19.57 & 21.38 & 38.86 \\
\hline 8 & Mudstone & 6.0 & 2597 & 3.83 & 7.42 & 4.39 & 30.41 \\
\hline 9 & Sandy mudstone & 8.0 & 2546 & 4.41 & 8.12 & 5.42 & 30.41 \\
\hline 10 & Coarse sandstone & 16.0 & 2541 & 10.94 & 13.45 & 21.63 & 29.98 \\
\hline 11 & Sandy mudstone & 9.0 & 2546 & 4.41 & 8.12 & 5.42 & 30.41 \\
\hline 12 & Mudstone & 8.0 & 2597 & 3.83 & 7.42 & 4.39 & 30.41 \\
\hline 13 & Coarse sandstone & 5.0 & 2541 & 10.94 & 13.45 & 21.63 & 29.98 \\
\hline 14 & Coal seam B4-1 & 3.0 & 1304 & 2.88 & 6.25 & 3.81 & 37.49 \\
\hline 15 & Mudstone & 8.0 & 2597 & 3.83 & 7.42 & 4.39 & 30.41 \\
\hline 16 & Coarse sandstone & 14.0 & 2541 & 10.94 & 13.45 & 21.63 & 29.98 \\
\hline 17 & Coal seam B3 & 1.8 & 1303 & 1.12 & 2.42 & 4.5 & 30.10 \\
\hline 18 & Mudstone & 3.0 & 2597 & 3.83 & 7.42 & 4.39 & 30.41 \\
\hline 19 & Packsand & 16.0 & 2618 & 14.07 & 19.57 & 21.38 & 28.86 \\
\hline 20 & Coal seam B2 & 9.5 & 1640 & 1.91 & 3.91 & 4.9 & 31.26 \\
\hline 21 & Mudstone & 4.0 & 2597 & 3.83 & 7.42 & 4.39 & 30.41 \\
\hline 22 & Packsand & & 2618 & 14.07 & 19.57 & 21.38 & 28.86 \\
\hline
\end{tabular}

Note: the top and bottom thickness of the model have different thickness with the change of dip angle. $T$ is the thickness; $\gamma$ is the unit weight, $G$ is the shear modulus; $K$ is the bulk modulus; $C$ is the cohesion; and $\varphi$ is the internal friction.

stress increment curve is stable at first in the mining process of W1123 but increases suddenly when the model is excavated to about $80 \mathrm{~m}$, and the high stress areas on both sides of the coal pillar are superimposed. (3) The peak stress increment fluctuates violently in the range of 80 to $150 \mathrm{~m}$, which reflects that the coal pillar is obviously affected by nonlinear loading at this stage, and the stress in the coal pillar changes significantly, which is easy to induce rock burst.

3.4. Variation of Stress in Different Positions of Coal Pillar. Seven monitoring points are arranged in the interior of the coal pillar, which are located at $10 \mathrm{~m}, 70 \mathrm{~m}, 130 \mathrm{~m}, 190 \mathrm{~m}$, $250 \mathrm{~m}, 310 \mathrm{~m}$, and $370 \mathrm{~m}$, respectively, of which $210 \mathrm{~m}$ is directly below the interface between the upper layer solid coal and the gob. The stress data of these seven points in the whole mining process are extracted. The stress curves at different positions of the coal pillar are shown in Figure 7.

By comparing the stress curves of different positions of the coal pillar (Figure 8), it is found that there is an obvious difference between the stress of coal pillar under solid coal and that under gob: (1) the position of the obvious increase of the stress of the coal pillar in the lower part of the solid coal is ahead of the advancing position of the working face, that is, when the working face is not mined to the current area, the stress of the coal pillar in this area has begun to increase. (2) The position of the obvious increase of the coal pillar stress in the lower part of the gob lags behind the advancing position of the working face, that is, the coal pillar stress in this area begins to increase obviously after the end of the current mining area of the working face.

\section{Design of Similar Material Model Experiment}

The related results show that the similar material simulation experiment can reproduce the structure in the mining process of the working face $[17,18]$. In order to further explore the rock burst mechanism under repeated mining in gently inclined extra thick coal seam, the roof hinged structure affected by repeated mining is studied by means of similar material simulation experiment.

4.1. Determining the Model Frame and Similarity Coefficient. The model test frame needs to be strong enough and has a certain width to ensure the stability of the model. A large number of researchers have explored the relationship between the ratio of simulated materials and the strength of real rock strata. The experimental model will be completely based on the on-site geological conditions of the Kuangou Coal Mine and the mining situation of working face.

In this experiment, the model will be constructed by using the experimental frame of $3000 \mathrm{~mm}^{*} 20 \mathrm{~mm}^{*} 1500$ $\mathrm{mm}$, and the W1123 and its overlying strata will be simulated by using sand as an aggregate and large white powder and gypsum powder as cementitious materials. The simulation of rock formation strength in the field is achieved by adjusting the ratio of different raw materials. Combining the 
$\mathrm{SZZ}(\mathrm{MPa})$

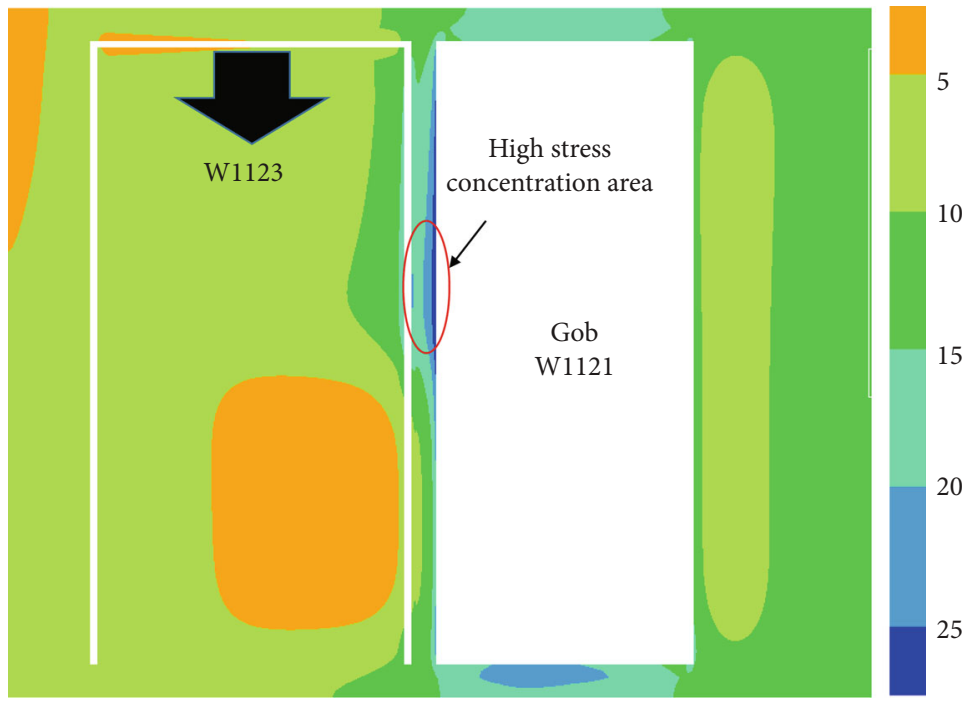

28.11

(a)

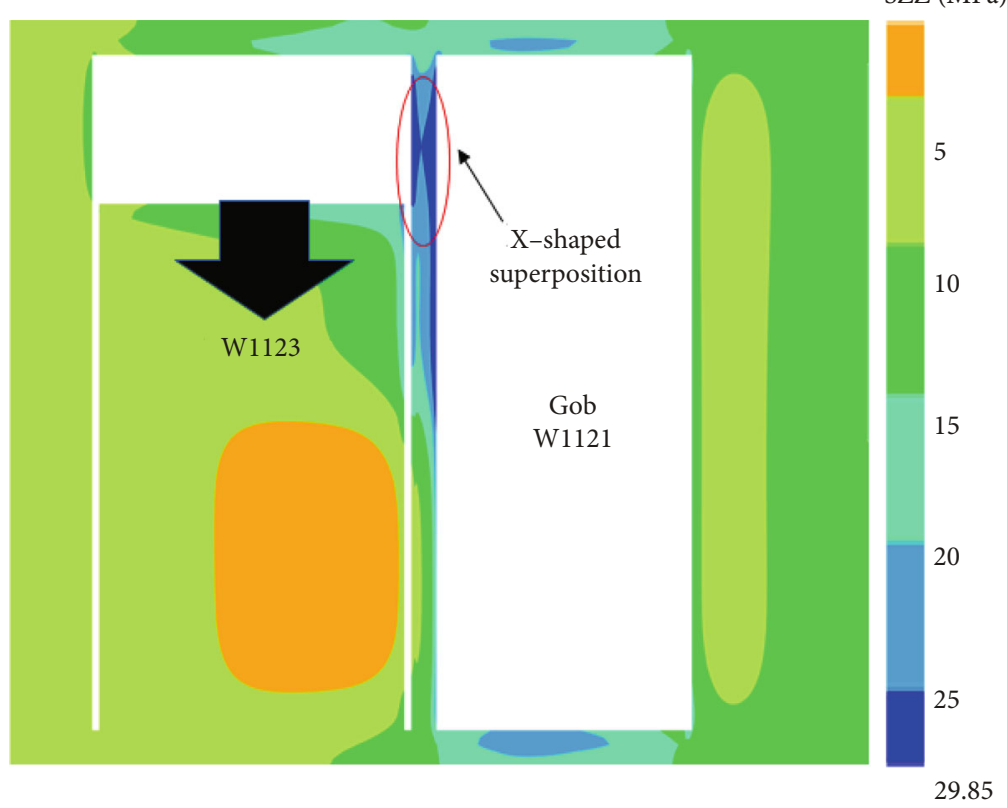

(b)

Figure 5: Vertical stress distribution of coal pillar: (a) advancing $0 \mathrm{~m}$ and (b) advancing $80 \mathrm{~m}$.

unilateral boundary conditions, then the constant of geometric similarity is as follows:

$$
\alpha_{l}=\frac{l_{m}}{l_{p}}=\frac{1}{200} .
$$

According to the properties of the chosen simulation material and the ratio of the material, the constant of bulk density similarity is as follows:

$$
\alpha_{r}=\frac{r_{m}}{r_{p}}=1
$$

According to similarity principle and dimensional analysis, the constant of geometric similarity $\alpha_{l}$, the constant of stress similarity $\alpha_{r}$, the constant of stress similarity $\alpha_{\sigma}$, and the constant of time similarity $\alpha_{t}$, at a certain relationship should be met.

$$
\alpha_{\sigma}=\alpha_{r} \alpha_{l}, \alpha_{t}=\sqrt{\alpha_{l}}
$$

Then, the constant of stress similarity is $\alpha_{\sigma}=0.081$, and the constant of time similarity is $\alpha_{t}=0.071$.

4.2. Ratio and Amount of Similar Material. Through the analysis of the experimental data of rock mechanics provided 


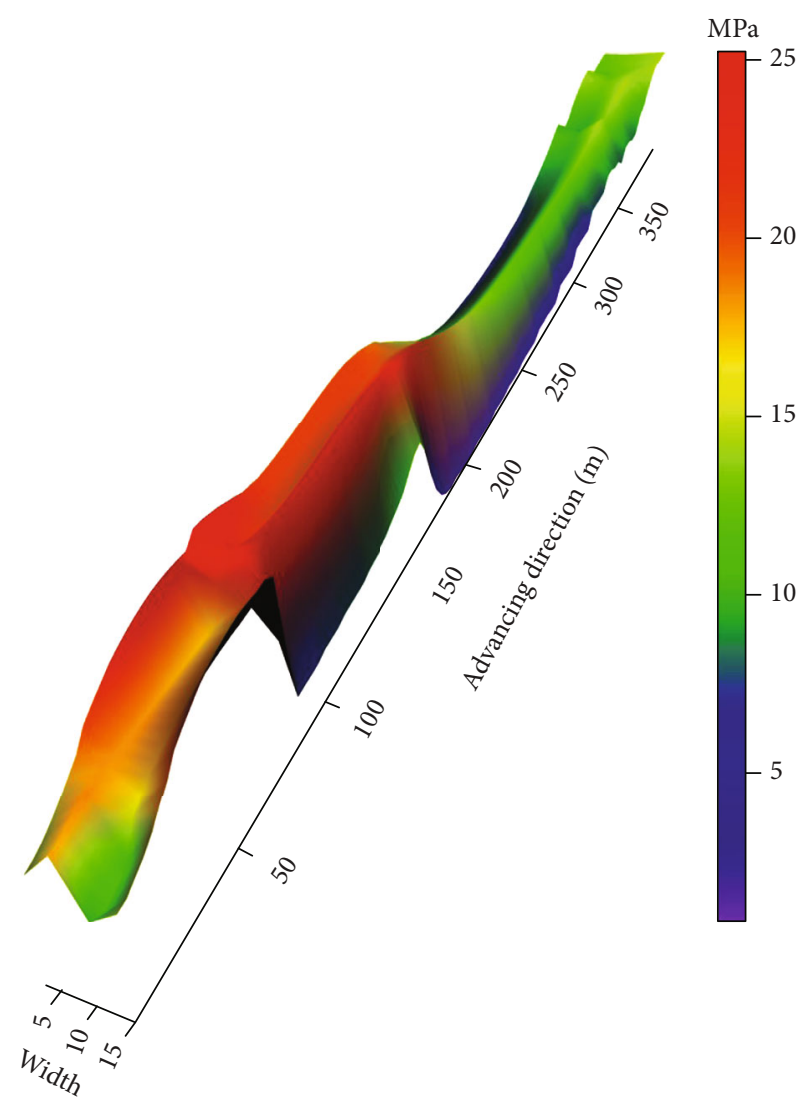

FIGURE 6: Relationship between peak stress of coal pillar and mining distance.

by the coal mine, the ratio of aggregate and cementitious materials is determined, and the model is made.

The specific ratio of the model material is as shown in Table 3, the ratio of aggregate : lime : large white powder gives the experimental value.

4.3. Structural Analysis. The results of similar material simulation experiments show that because the roof of the B2 coal seam is composed of a layer of extremely thick and hard fine sandstone; therefore, in the gob, it will not be fully broken under the action of gravity as other roofs, but to form a certain degree of integrity of the block. Because the block near the coal pillar does not have enough space to collapse, a kind of roof hinged structure is formed which is shown in Figures 9 and 10 .

The roof hinged structure is shown in Figure 11, where $\alpha=14^{\circ}, \beta$ is the angle between the rock block and the horizontal direction, and $\gamma$ is the rotation angle of the rock block. The geometric relationship of the rock block in the process of rotation is shown in Figure 12.

In addition, when the extrusion pressure is linearly distributed along the interface, the position of the resultant force action point is $n=p / 3$ [19]. The thickness and weight of the rock mass are much smaller than the thickness and weight of the overlying strata;therefore, in the process of calculation, the weight of the rotating rock block itself is ignored and the length of the rotating rock block is much smaller than that of the overlying strata; so, the load above the rotating rock block is simplified to a uniformly distributed load, and the force analysis is shown in Figure 13. From the force analysis, the following is obtained.

For mechanical condition,

$$
\begin{aligned}
R_{D} & =R_{B}, \\
T_{D}+q L \tan \gamma & =T_{B}, \\
R_{D}+R_{B} & =q L, \\
T_{D} \mathrm{~b}+R_{D} 1 & =\frac{q L^{2}}{2} .
\end{aligned}
$$

For geometric condition,

$$
\begin{aligned}
& \mathrm{b}=\frac{L^{\prime} \sin \gamma}{\cos 14^{\circ}} \approx \frac{L \sin \gamma}{\cos 14^{\circ}}, \\
& 1 \approx \frac{L^{\prime} \cos \gamma}{\cos 14^{\circ}} \approx \frac{L \cos \gamma}{\cos 14^{\circ}} .
\end{aligned}
$$

According to Equations (4)-(9),

$$
T_{D}=\frac{\mathrm{q} L}{2} \bullet \frac{\cos 14^{\circ}-\cos \gamma}{\sin \gamma} .
$$

For the derivation of $\gamma$,

$$
T_{D}{ }^{\prime}=\frac{\mathrm{q} L}{2} \bullet \frac{1-\sin \gamma-\cos 14^{\circ}}{\sin ^{2} \gamma} \text {. }
$$

In the process of roof rotation $0<\gamma<90^{\circ}$, so $T_{D}{ }^{\prime}>0$ $\left(0<\gamma<90^{\circ}\right), T_{D}$ is a monotone increasing function about $\gamma$ in the process of rotation.

When the excavation of W1121 is over, the roof hinged structure appears only on one side of the pillar (Figure 14(a)). The weight of some of the overlying strata is borne by the unilateral roof hinged structure formed by the W1121 gob. Therefore, the roof is bound to produce unilateral stress concentration at this time. And the roof hinged structure is a transitional state, and with the passage of time, the gob is gradually compacted under the load of the overlying strata, and the free space formed at this time will make the roof hinged structure rotate along the hinge point. The process of rotation will inevitably squeeze the roof on the coal pillar, which aggravates the degree of unilateral stress concentration. In addition, the coal quality of the B2 coal seam is hard, and the roof of the B2 coal seam also has impact tendency. So, a large number of elastic properties can be stored in the coal pillar, which provides an energy storage basis for the occurrence of rock burst, and the possibility and risk of dynamic disasters are obviously increased.

When the excavation of W1123 is over, the roof hinged structure appears on both sides of the coal pillar (Figure 14(b)). At this time, the coal pillar is affected by the bilateral roof hinged structure, which will inevitably produce bilateral stress concentration, and the average inclination angle of the B2 coal seam is $14^{\circ}$. The influence of the 


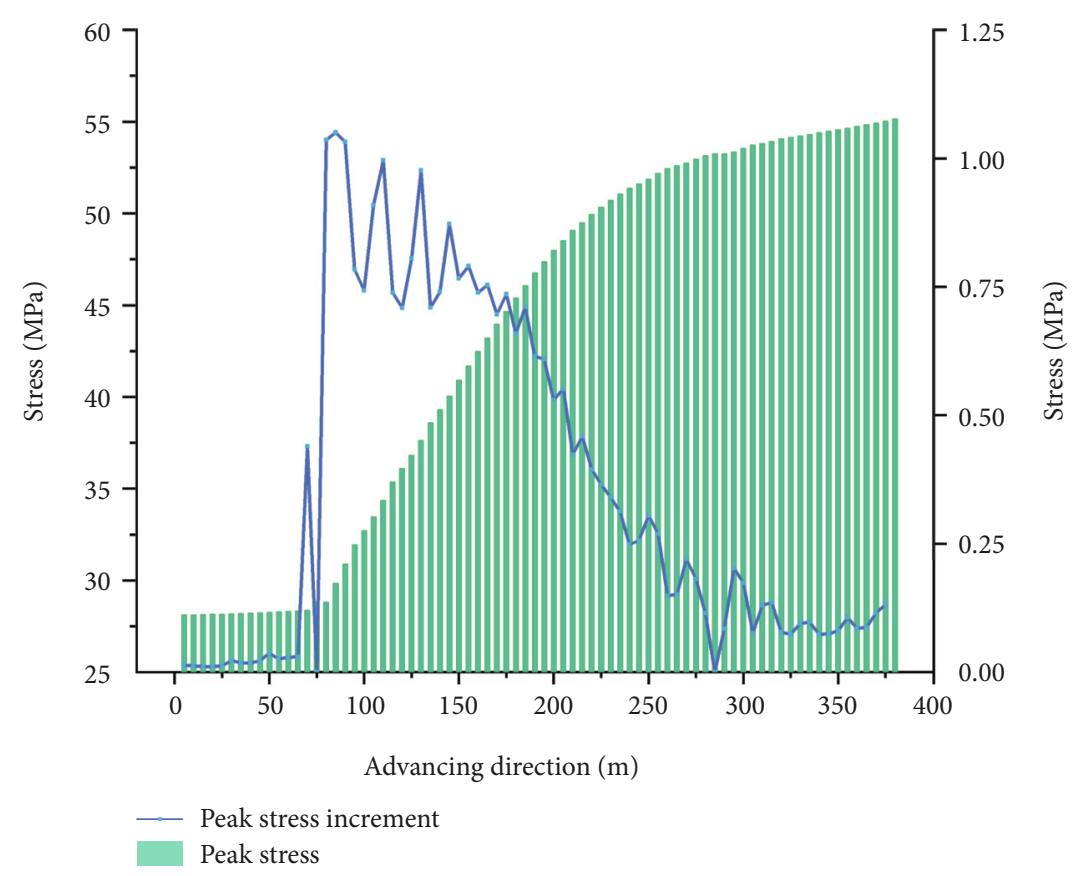

FIgURE 7: Spatial distribution of stress field in coal pillar.

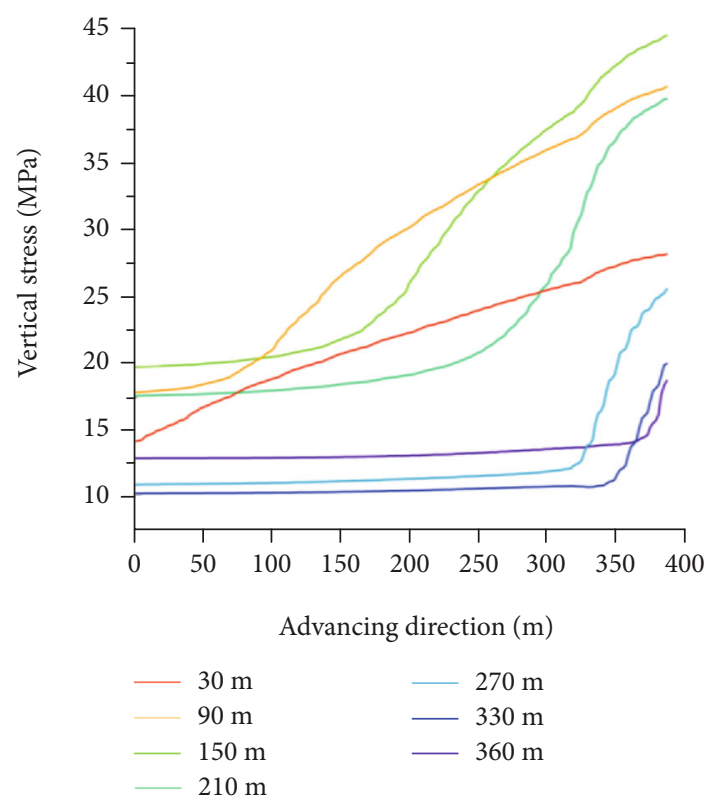

FIGURE 8: Relationship between different positions and stress variation in coal pillar.

W1123 side structure on the internal structure of the roof is greater than that of the W1121 side structure.

\section{Analysis of Dynamic Load Source}

Based on the above analysis, the internal elastic performance of the coal pillar has accumulated greatly under the influence of the overlying coal body and the roof hinged structure in the gob, and if it is affected by the impact load, the instanta- neous storage energy of coal pillar and roof may exceed the limit of its storage and release most of the energy for a short time, resulting in rock burst.

5.1. Dynamic Load by Key Stratum. Through the above analysis, the instability of the key strata structure formed during the overlying rock failure caused by coal seam mining is the dynamic cause of rock burst. There is a key strata with the thickness of $14 \mathrm{~m}$ above the W1123 working face. When the key strata structure breaks, it will hit the collapsed strata under the action of gravity and produce an elastic wave at the same time. When the elastic wave passes through the coal pillar which has reached the critical state, the coal pillar will instantly release a lot of energy and reflect it in the form of a rock burst.

5.2. Dynamic Load by Periodic Pressure. The data of hydraulic support sensor in the W1123 working face, 31 days before and 8 days after the impact event, support pressure distribution as shown in Figure 15.

It can be seen from the diagram that there is a small periodic weighting in the W1123 working face around February 17. The period ended on February 18 and lasted for three days. The period reappeared around March 5 and ended on March 9 for a total of five days. The scale of the second period is wider, and the strength is larger than that of the previous one. And the impact event happens to be in the time period of large-scale weighting in the working face, so the periodic weighting of the W1123 working face is also one of the causes of the impact event.

5.3. Dynamic Load by Earthquake. The Kuangou Coal Mine is located in the Shawan County-Manas County-Hutubi County earthquake belt, where there are frequent earthquakes; 
TABLE 3: Experiment ratio.

\begin{tabular}{|c|c|c|c|c|c|c|}
\hline No. & Lithology & Simulated thickness $(\mathrm{cm})$ & Material proportion & Sand $(\mathrm{kg})$ & Gypsum (kg) & Flour $(\mathrm{kg})$ \\
\hline 1 & Mudstone & & $40: 3: 7$ & 13.87 & 0.52 & 1.21 \\
\hline 2 & Sandy mudstone & 6 & $20: 1: 4$ & 13.6 & 0.34 & 1.36 \\
\hline 3 & Mudstone & 5 & $40: 3: 7$ & 13.87 & 0.52 & 1.21 \\
\hline 4 & Sandy mudstone & 7 & $20: 1: 4$ & 13.6 & 0.34 & 1.36 \\
\hline 5 & Sandstone & 6 & $45: 1: 4$ & 13.3 & 0.29 & 1.18 \\
\hline 6 & Sandy mudstone & 4 & $20: 1: 4$ & 13.6 & 0.34 & 1.36 \\
\hline 7 & Packsand & 4 & $70: 9: 21$ & 13.76 & 0.59 & 1.38 \\
\hline 8 & Mudstone & 3 & $40: 3: 7$ & 13.87 & 0.52 & 1.21 \\
\hline 9 & Sandy mudstone & 7 & $20: 1: 4$ & 13.6 & 0.34 & 1.36 \\
\hline 10 & Coarse sandstone & 8 & $35: 3: 12$ & 13.34 & 0.38 & 1.52 \\
\hline 11 & Sandy mudstone & 4.5 & $20: 1: 4$ & 13.6 & 0.34 & 1.36 \\
\hline 12 & Mudstone & 4 & $20: 1: 4$ & 13.6 & 0.34 & 1.36 \\
\hline 13 & Coarse sandstone & 2.5 & $35: 3: 12$ & 13.34 & 0.38 & 1.52 \\
\hline 14 & Coal seam B4-1 & 1.5 & $20: 20: 1: 1.5$ & 5.085 & 0.254 & 1.272 \\
\hline 15 & Mudstone & 4 & $40: 3: 7$ & 13.87 & 0.52 & 1.21 \\
\hline 16 & Coarse sandstone & 7 & $35: 3: 12$ & 13.34 & 0.38 & 1.52 \\
\hline 17 & Coal seam B3 & 0.9 & $20: 20: 1: 1.5$ & 3.39 & 0.169 & 0.848 \\
\hline 18 & Mudstone & 1.5 & $40: 3: 7$ & 20.81 & 0.78 & 1.82 \\
\hline 19 & Packsand & 8 & $70: 9: 21$ & 13.76 & 0.59 & 1.38 \\
\hline 20 & Coal seam B2 & 4.75 & $20: 20: 1: 1.5$ & 4.28 & 0.22 & 1.07 \\
\hline 21 & Mudstone & 2 & 837 & 13.87 & 0.52 & 1.21 \\
\hline 22 & Packsand & & $70: 9: 21$ & 536 & 23 & 54 \\
\hline
\end{tabular}

Note: the top and bottom thickness of the model have different thickness with the change of dip angle. The material proportion of rock is aggregate : gypsum : flour. The material proportion of coal seam is aggregate : gypsum : flour : pulverized coal.

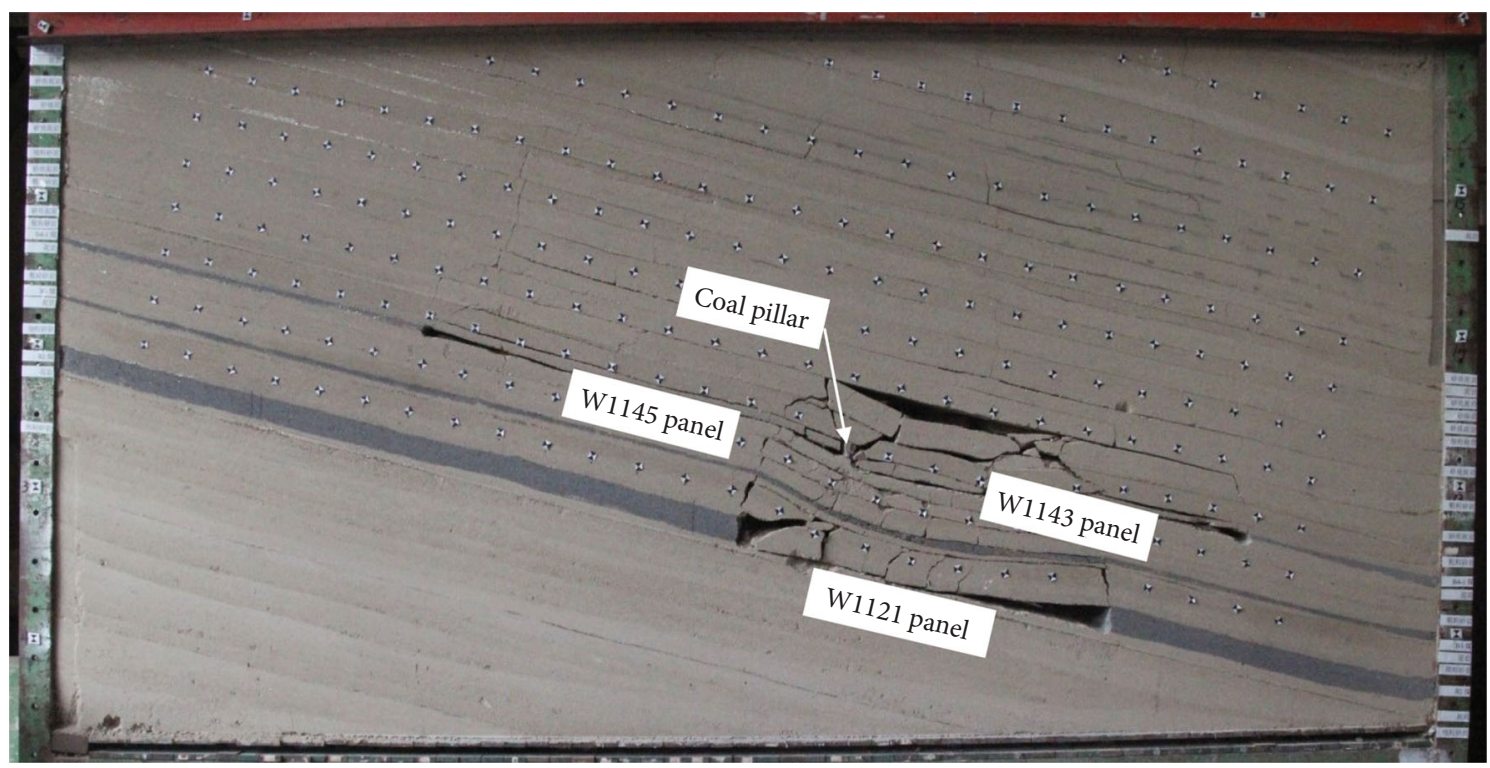

FIGURE 9: Characteristics of overlying strata in W1121working face mining.

this area is an earthquake-prone area. Therefore, the elastic wave caused by the earthquake can apply a dynamic load to working face which may trigger the rockburst to occur, but the earthquake did not occur on the March 7, so the earthquake has nothing to do with the occurrence of
March 7 coal pillar rock burst, but enough attention should be paid to it. Because of the high degree of unpredictability of the seismic activity, the prevention and control measures of rock burst must be included in the daily work. 


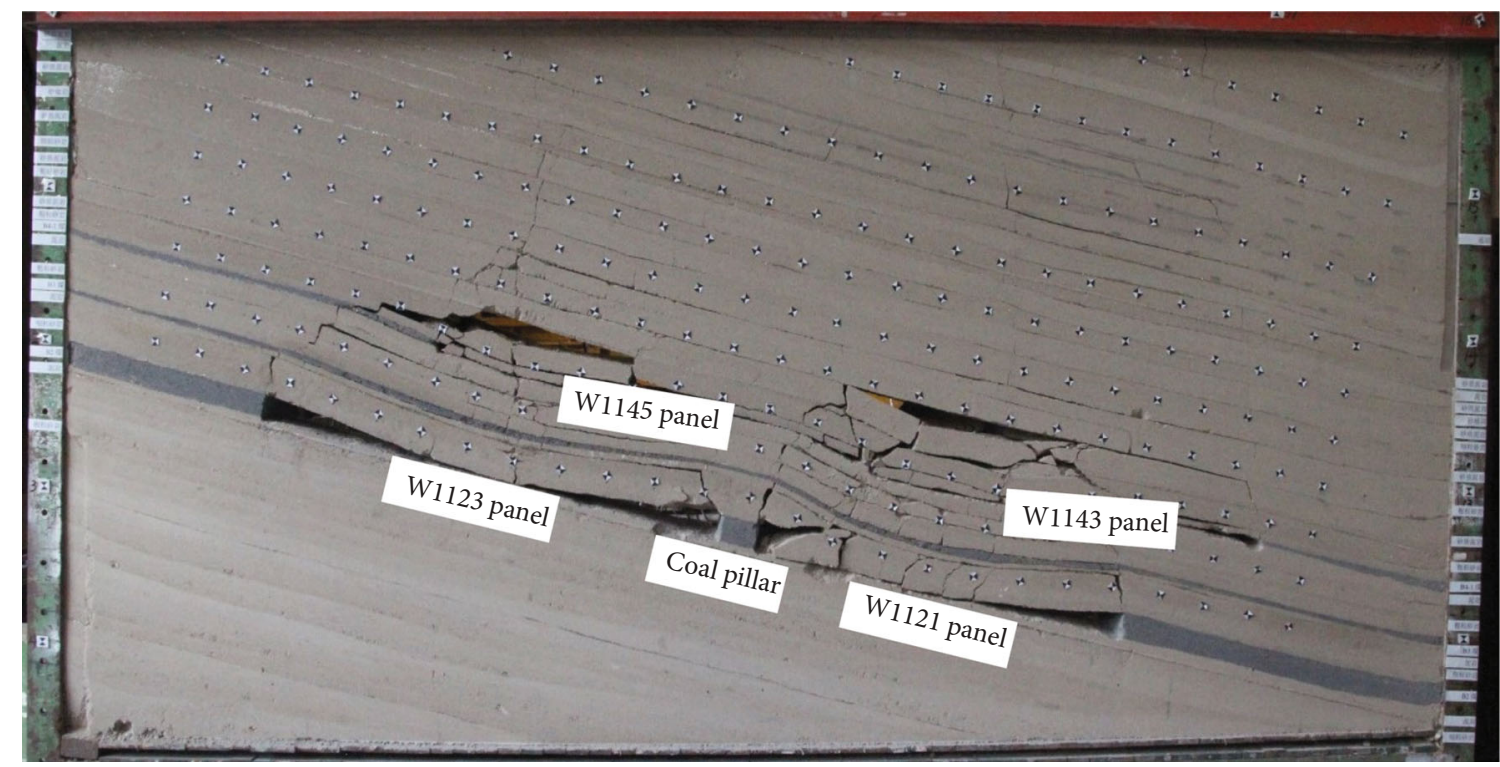

FIGURE 10: Characteristics of overlying strata in W1123 working face mining.

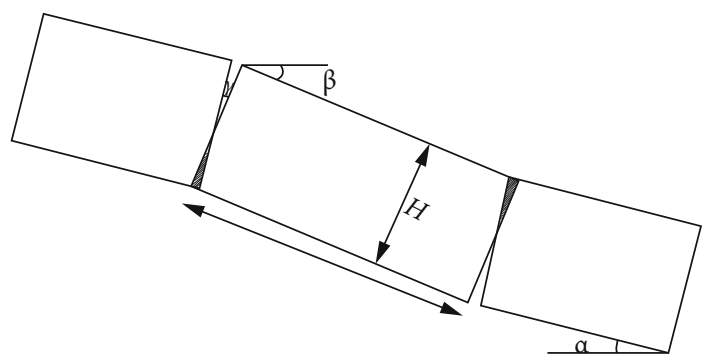

Figure 11: Indication of roof hinged structure.

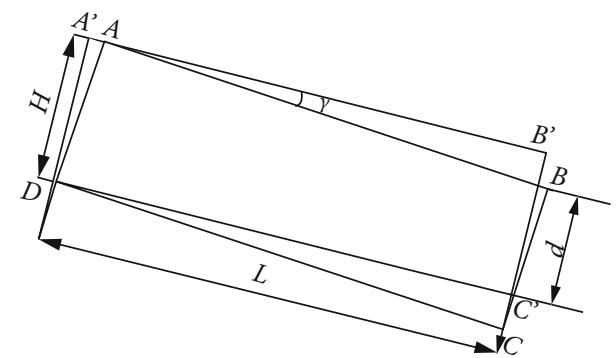

Figure 12: Geometric relations when rock rotates.

\section{Pressure Relief Measures of Coal Seam}

6.1. Rock Mass Engineering. The roof of coal seam is one of the most important factors affecting the occurrence of rock burst.

Roof blasting is to break the roof, reduce its strength, release the energy gathered due to pressure, and reduce the impact vibration to the coal seam and support. The rock mass engineering is divided into two parts, namely, the roof advance precracking and the end advance precracking of the end.

6.1.1. Calculation of Blasting Parameters. The average mining height of the W1123 working face is $11 \mathrm{~m}$, the roof caving thickness is set, and the rock swelling coefficient is 1.4. In order to ensure that the caving roof can fully fill the goaf, the following formula is valid [20]:

$$
H_{x} \bullet \xi=H_{C}+H_{x} .
$$

After calculation, $H_{x}=11 /(1.4-1)=27.5 \mathrm{~m}$.

According to the geological conditions of the Kuangou Coal Mine, the upper $33 \mathrm{~m}$ of the B2 coal seam is the B3 coal seam. According to the calculation of roof treatment height, in order to leave a certain surplus coefficient, it is tentatively determined that the roof rock treatment range of the W1123 working face is along the vertical height from the roof of the working face to the upper $27 \mathrm{~m}$.

Because there is a certain gap in the lower $27 \mathrm{~m}$ collapse area, the pressure caused by the natural collapse of the remaining $6 \mathrm{~m}$ rock will be effectively degraded and will not produce a strong impact risk.

The roof is weakened by deep-hole blasting, and the diameter of the hole is generally $70 \mathrm{~mm} \sim 100 \mathrm{~mm}$. When the blasthole diameter is small, the charge is more difficult, and the blasting influence range is proportional to the blasthole blasting diameter. The blasting effect is poor when the blasthole diameter is small, but when the blasthole diameter is too large, it is difficult to seal the mud, which will affect the blasting effect. Therefore, the vertical diameter of the roof blasthole weakened by deep-hole blasting should not be too large or too small. According to the experience of other working faces during mining, the blasthole diameter is determined to be $94 \mathrm{~mm}$.

After the explosive explosion, the crushing zone, crack zone, and vibration zone are formed from the explosion source outward.

By calculating the range of the crack zone produced by blasting, the reasonable hole spacing can be determined.

Because the blasting is carried out without free surface, the range of the crack zone of the pressure relief blasting is 


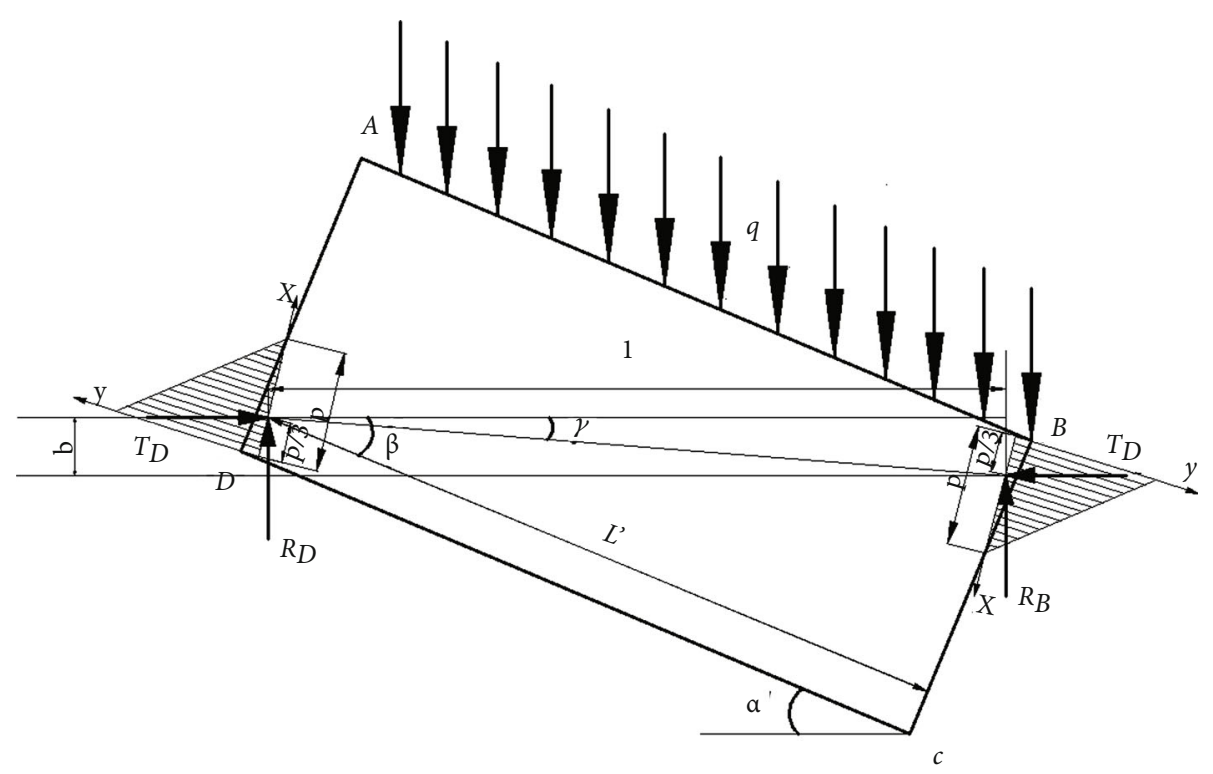

FIgURE 13: Force analysis and geometric analysis.

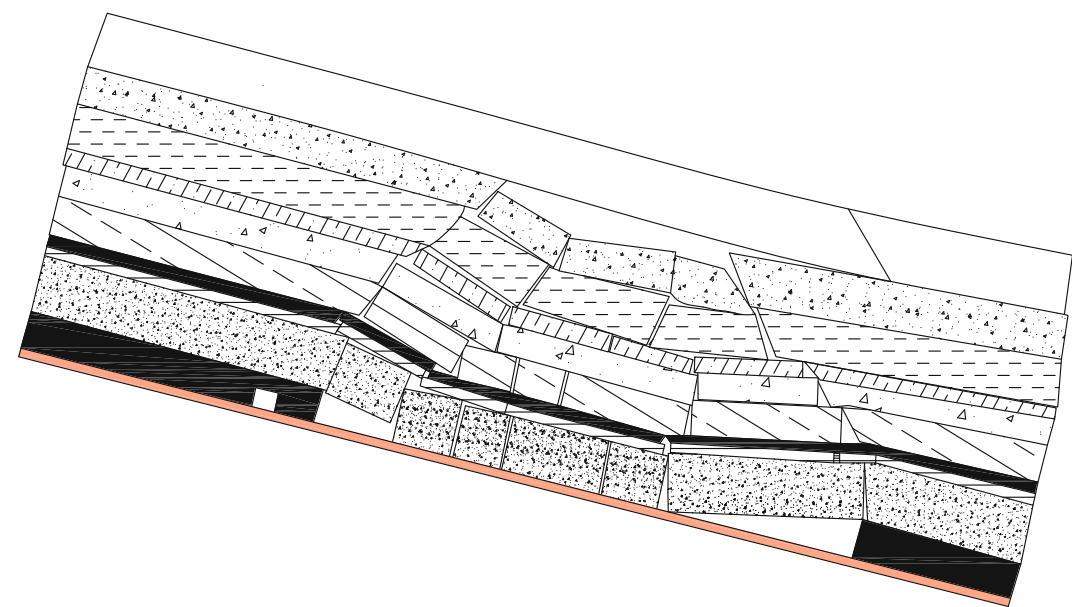

(a)

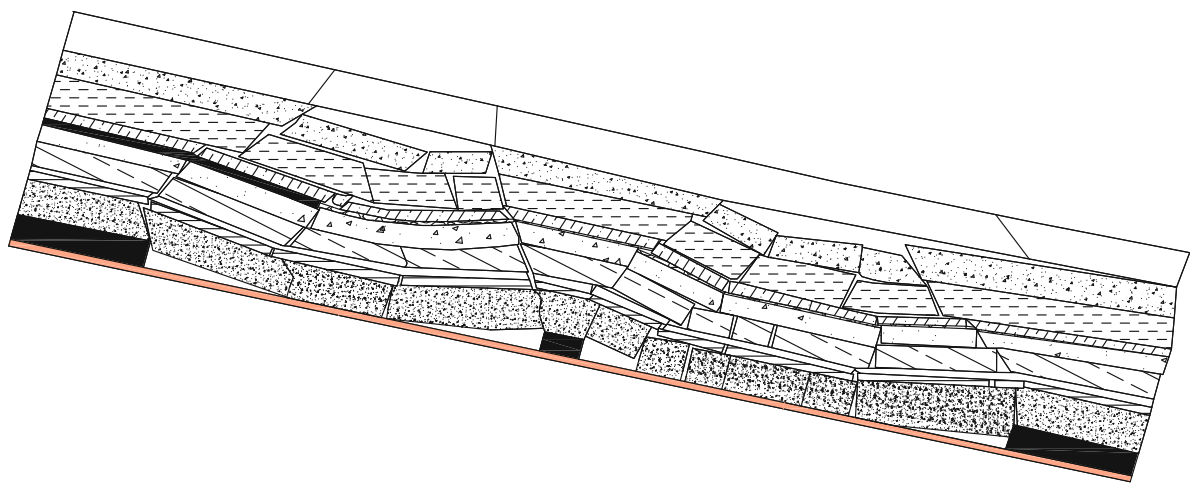

(b)

FIGURE 14: Roof hinged structure in different mining stages. (a) Structure in gob W1121. (b) Structure in gob W1123. 


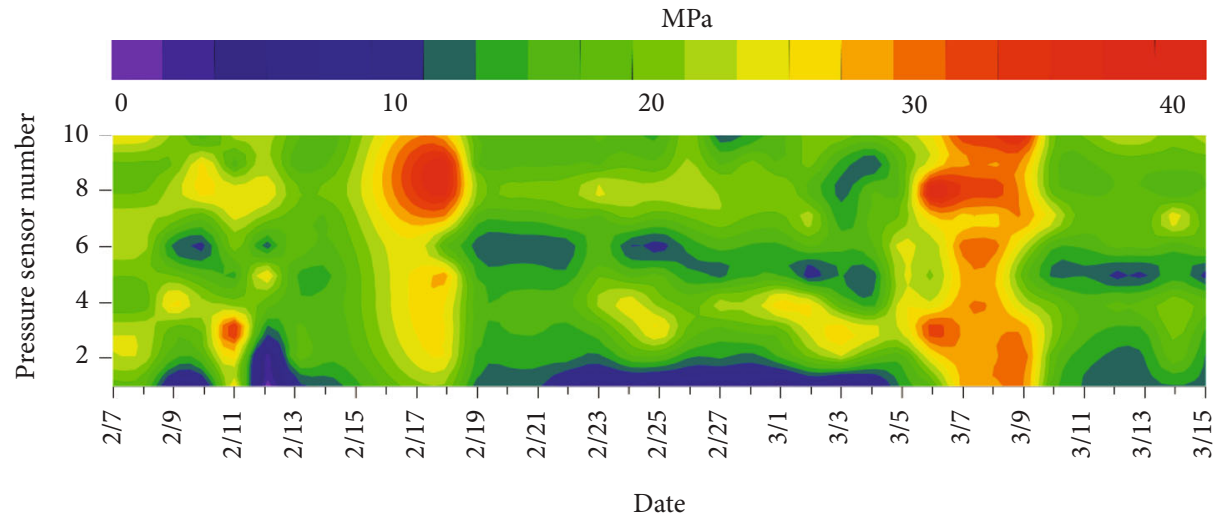

FIgURE 15: Support pressure distribution.

calculated according to the explosion stress wave in the case of uncoupled charge.

In the blasting of uncoupled charge, the peak value of radial stress acting on the hole wall, that is, the initial impact pressure $P_{r}$ can be expressed as $[21,22]$ :

$$
P_{r}=\frac{1}{8} \rho_{e} D^{2}\left[\frac{d_{c}}{d_{b}}\right]^{6} n,
$$

where $\rho_{e}$ is the explosive density, taking $1.27 \times 103 \mathrm{~kg} / \mathrm{m}^{3} ; D$ is the explosion velocity, taking $4400 \mathrm{~m} / \mathrm{s} ; d_{c}$ is the explosive diameter, taking $90 \mathrm{~mm}$; $d_{b}$ is the blast hole diameter, taking $94 \mathrm{~mm}$; and $n$ is the stress increase multiple caused by explosive gas colliding with the rock, taking 12 . After calculation $P_{r}$ is $29411 \mathrm{MPa}$.

Crack radius $R$ can be expressed as $[23,24]$

$$
R=\left(\frac{(\nu /(1-v)) P_{r}}{\sigma_{t}}\right)^{1 / a} r_{b}
$$

where $v$ is the Poisson ratio of rock, taking $0.2 ; \sigma_{t}$ is the tensile strength, taking 7.48 MPa; $a$ is the attenuation index, taking 1.5; and $r_{b}$ is the Blasthole radius; taking $47 \mathrm{~mm}$. After calculation, $R$ is $9081 \mathrm{~mm}$.

According to the abovementioned mechanical parameters of the roof and the performance parameters of the no. 3 emulsion explosive, the calculated results show that the diameter of the crack zone is larger than that of $9000 \mathrm{~mm}$.

Therefore, under the condition of ensuring enough safety, the roof of the working face is precracked at the same time, so that the roof cannot have a stress concentration, so the blast hole spacing is set as $10000 \mathrm{~mm}$.

In cylindrical charge blasting, the explosion resistance of coal and rock mass increases with the increase of blasthole depth, and the blasting ability of explosive is related to the length of plugging hole and the explosion resistance of coal and rock mass.

If the plugging length is too short and the explosion resistance is reduced, the throwing funnel will affect the blasting effect during the explosion, especially the stability and support of the trench will be destroyed.
If the plugging length is greater than its critical length, the blasting capacity of coal and rock is less than the antiexplosion capacity, and the coal and rock mass of the plugging section cannot form cracks during explosion, which also affects the blasting effect.

Therefore, a reasonable plugging length should not only ensure that the coal and rock mass in the plugging section is loose and presplit but also cannot produce a throwing funnel at the same time.

According to the general situation, the plugging length of deep-hole blasting should be $25 \%-30 \%$ of the hole depth, but considering that the blasting point is close to the roof of the coal seam, it is easy to cause roof leakage in front of the shelf. According to experience, the blasting point should be controlled above $4 \mathrm{~m}$ above the roof of the coal seam. Due to the limited space, the rest of the schemes are also calculated according to this method; it will not be repeated later.

6.1.2. Roof Precracking. Construction begins at a distance of $30 \mathrm{~m}$ from the working face, and every $10 \mathrm{~m}$ a group of blastholes are arranged perpendicular to the center line of the roadway. The layout of the blasthole is shown in Figure 16. The parameters of blasting hole drilling and filling explosive is shown in Table 4.

6.1.3. End Precracking. In order to prevent the extremely thick and hard roof from forming a hinged structure on both sides of the coal pillar, it is necessary to blasting the side roof of the coal pillar. The blasting hole at the end is $20 \mathrm{~m}$ away from the workingface. There are three boreholes in each group of the headgate, with a depth of $30 \mathrm{~m}$ and a step of $5 \mathrm{~m}$, and two boreholes in each group of the tailgate, with a depth of $30 \mathrm{~m}$ and a step of $5 \mathrm{~m}$. The layout of the blasthole is shown in Figure 17. The parameters of blasting hole drilling and filling explosive is shown in Table 5.

\subsection{Coal Body Engineering}

6.2.1. Coal Seam Deep-Hole Blasting. The technological roadway is not only used to deal with the roof but also the coal seam deep-hole blasting is used to presplit the top coal. The hole spacing is $5 \mathrm{~m}$ and the hole diameter is $94 \mathrm{~mm}$. The layout of the blasthole is shown in Figure 18. The parameters of 


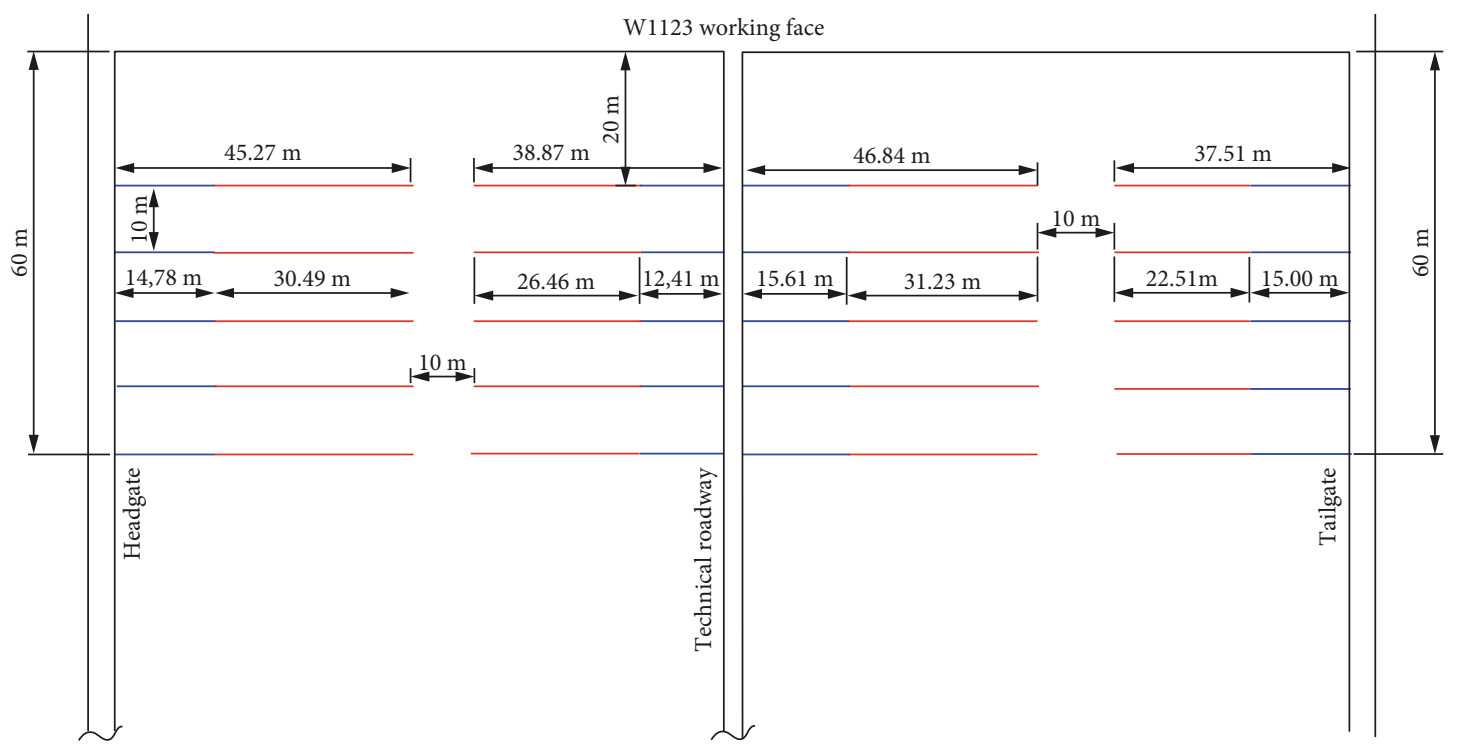

(a)

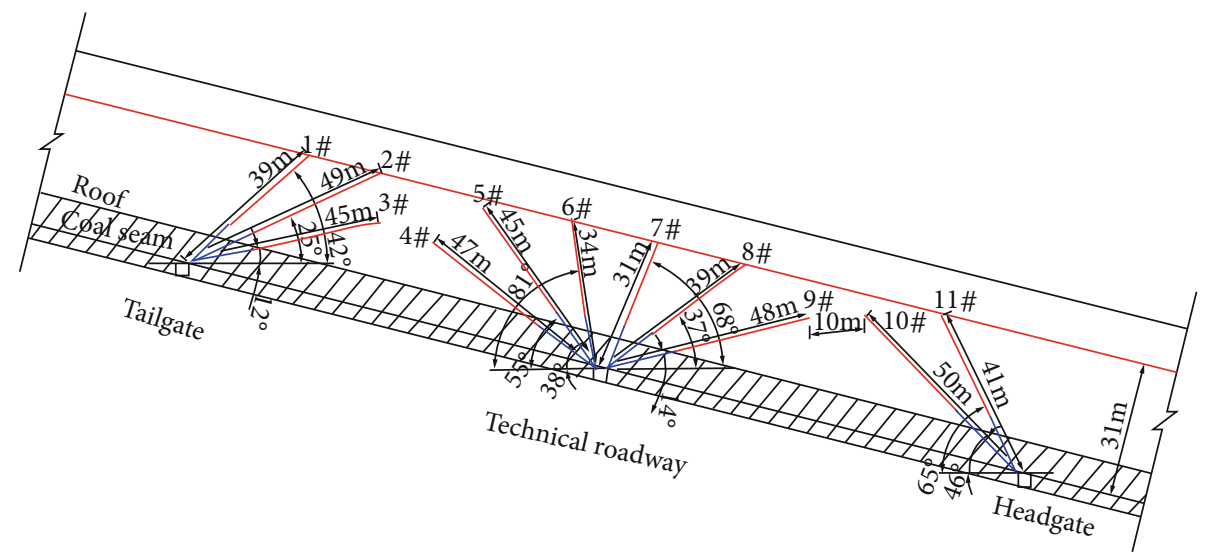

(b)

FIGURE 16: Roof precracking blasthole layout scheme. (a) Plane diagram. (b) Section diagram.

TABLE 4: Parameters of roof precracking blasthole drilling and filling explosive.

\begin{tabular}{|c|c|c|c|c|c|c|c|}
\hline $\begin{array}{l}\text { Hole } \\
\text { number }\end{array}$ & $\begin{array}{l}\text { Borehole } \\
\text { length }(\mathrm{m})\end{array}$ & $\begin{array}{l}\text { Horizontal } \\
\text { angle }\left({ }^{\circ}\right)\end{array}$ & $\begin{array}{c}\text { Elevation } \\
\text { angle }\left(^{\circ}\right)\end{array}$ & $\begin{array}{l}\text { Borehole diameter } \\
\qquad(\mathrm{mm})\end{array}$ & $\begin{array}{l}\text { Filling explosive } \\
\text { length }(\mathrm{m})\end{array}$ & $\begin{array}{l}\text { Plugging } \\
\text { length }(\mathrm{m})\end{array}$ & $\begin{array}{l}\text { Explosive filling } \\
\text { weight }(\mathrm{kg})\end{array}$ \\
\hline 1 & 39 & 90 & 42 & 94 & 26 & 13 & 130 \\
\hline 2 & 49 & 90 & 25 & 94 & 33 & 16 & 165 \\
\hline 3 & 45 & 90 & 12 & 94 & 30 & 15 & 150 \\
\hline 4 & 47 & -90 & 38 & 94 & 32 & 15 & 160 \\
\hline 5 & 45 & -90 & 55 & 94 & 30 & 15 & 150 \\
\hline 6 & 34 & -90 & 81 & 94 & 22 & 12 & 110 \\
\hline 7 & 31 & 90 & 68 & 94 & 21 & 10 & 105 \\
\hline 8 & 39 & 90 & 37 & 94 & 26 & 13 & 130 \\
\hline 9 & 48 & 90 & 14 & 94 & 32 & 16 & 160 \\
\hline 10 & 50 & -90 & 46 & 94 & 30 & 20 & 75 \\
\hline 11 & 41 & -90 & 65 & 94 & 26 & 15 & 65 \\
\hline
\end{tabular}

Note: the horizontal angle is the angle between the drilling direction and the center line of the roadway. Elevation angle is the angle between the drilling direction and the horizontal line of the roadway. 


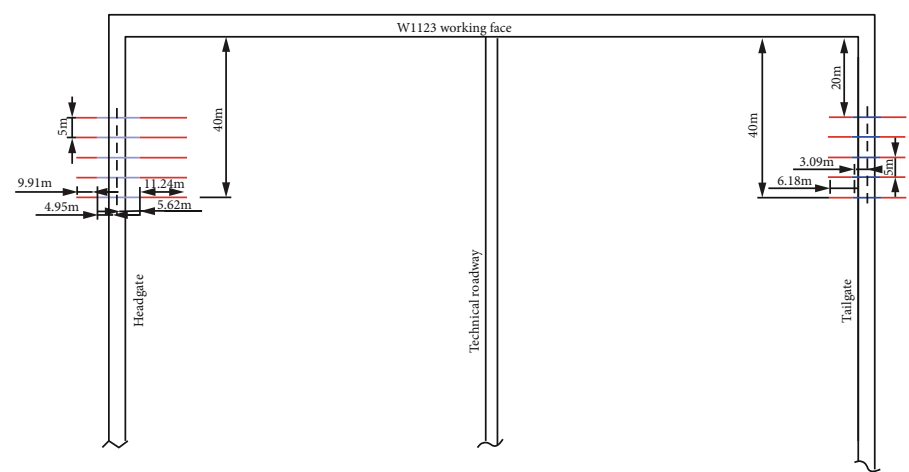

(a)

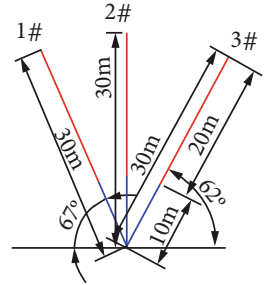

(b)

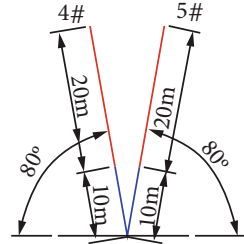

(c)

Figure 17: End precracking blasthole layout scheme. (a) Plane diagram. (b) Section diagram in the headgate. (c) Section diagram in the tailgate.

TABLe 5: Parameters of end precracking blasthole drilling and filling explosive.

\begin{tabular}{lccccccc}
\hline $\begin{array}{l}\text { Hole } \\
\text { number }\end{array}$ & $\begin{array}{c}\text { Borehole } \\
\text { length }(\mathrm{m})\end{array}$ & $\begin{array}{c}\text { Horizontal } \\
\text { angle }\left(^{\circ}\right)\end{array}$ & $\begin{array}{c}\text { Elevation } \\
\text { angle }\left(^{\circ}\right)\end{array}$ & $\begin{array}{c}\text { Borehole diameter } \\
(\mathrm{mm})\end{array}$ & $\begin{array}{c}\text { Filling explosive } \\
\text { length }(\mathrm{m})\end{array}$ & $\begin{array}{c}\text { Plugging } \\
\text { length }(\mathrm{m})\end{array}$ & $\begin{array}{c}\text { Explosive filling } \\
\text { weight }(\mathrm{kg})\end{array}$ \\
\hline 1 & 30 & -90 & 67 & 94 & 20 & 10 & 100 \\
2 & 30 & 0 & 90 & 94 & 20 & 10 & 10 \\
3 & 30 & 90 & 62 & 94 & 20 & 10 & 100 \\
4 & 30 & -90 & 80 & 94 & 20 & 50 & 10 \\
5 & 30 & 90 & 80 & 94 & 50 & 10 \\
\hline
\end{tabular}

Note: the horizontal angle is the angle between the drilling direction and the center line of the roadway. Elevation angle is the angle between the drilling direction and the horizontal line of the roadway.

blasting hole drilling and filling explosive are shown in Table 6.

6.2.2. Large Diameter Drilling. The construction of large diameter pressure relief borehole in the coal body can release the elastic property accumulated in the coal body and eliminate stress accumulation. In the impact danger area, the stress value of the roof strata acting on the coal body reaches the critical stress state of the coal body. When the borehole is squeezed and deformed, the stress of the coal body is released and reduced to a new energy balance point in the process of deformation, thus reaching below the limit stress of the coal body impact and avoiding the occurrence of rock burst.

The diameter of the drill bit is $153 \mathrm{~mm}$, the drilling depth is $90 \mathrm{~m}$, and the hole spacing is $8 \mathrm{~m}$. Pressure relief boreholes are constructed along the coal seam.

6.3. Verification of Pressure Relief Measures. Take the data collected by microseismic monitoring equipment as an example. Analyze the number of events and energy collected by the microseismic equipment in the working face before and after the implementation of the treatment measures and extract them as shown in Figure 19.

On the day before the rock burst, the total energy of microearthquakes has been greatly increased, indicating that the elastic performance of the working face is gathering and finally reaches the cumulative limit at March 7, which leads to the occurrence of impact events. After the above blasting pressure relief measures, the total energy of microseismic events in the working face decreased greatly on March 8 , and was lower than that produced in other normal mining periods. Therefore, it can be judged that the degree of elastic agglomeration of the blasting W1123 working face has been greatly reduced, and the pressure relief scheme is effective.

\section{Rockburst Control Method and Strategy}

According to the analysis above, two aspects affect the internal stress of the coal pillar. On the one hand, the coal pillar carries the static load of the strata above; on the other hand, it is the dynamic load caused by mining in the working face. The dynamic load caused by the sudden collapse of the key strata after reaching the limit span with the increase of the mining space is the main reason for the rock burst. The coal pillar can still maintain its own steady state under the influence of mining, but it is close to the equilibrium limit. At this time, if the energy produced by the structural instability of the key strata will cause the equilibrium limit failure, it is very likely to cause rock burst. Therefore, the prevention and control methods of rock burst in the W1123 working face should be considered from the following two aspects, as shown in Figure 20.

(i) The rock mass engineering: the advance precracking of the roof will weaken the impact load caused by the breaking of the key strata, because the roof will play a bearing role on the overlying strata, and the treatment of the roof in time will dissipate actively the elastic energy accumulated above the roof under 


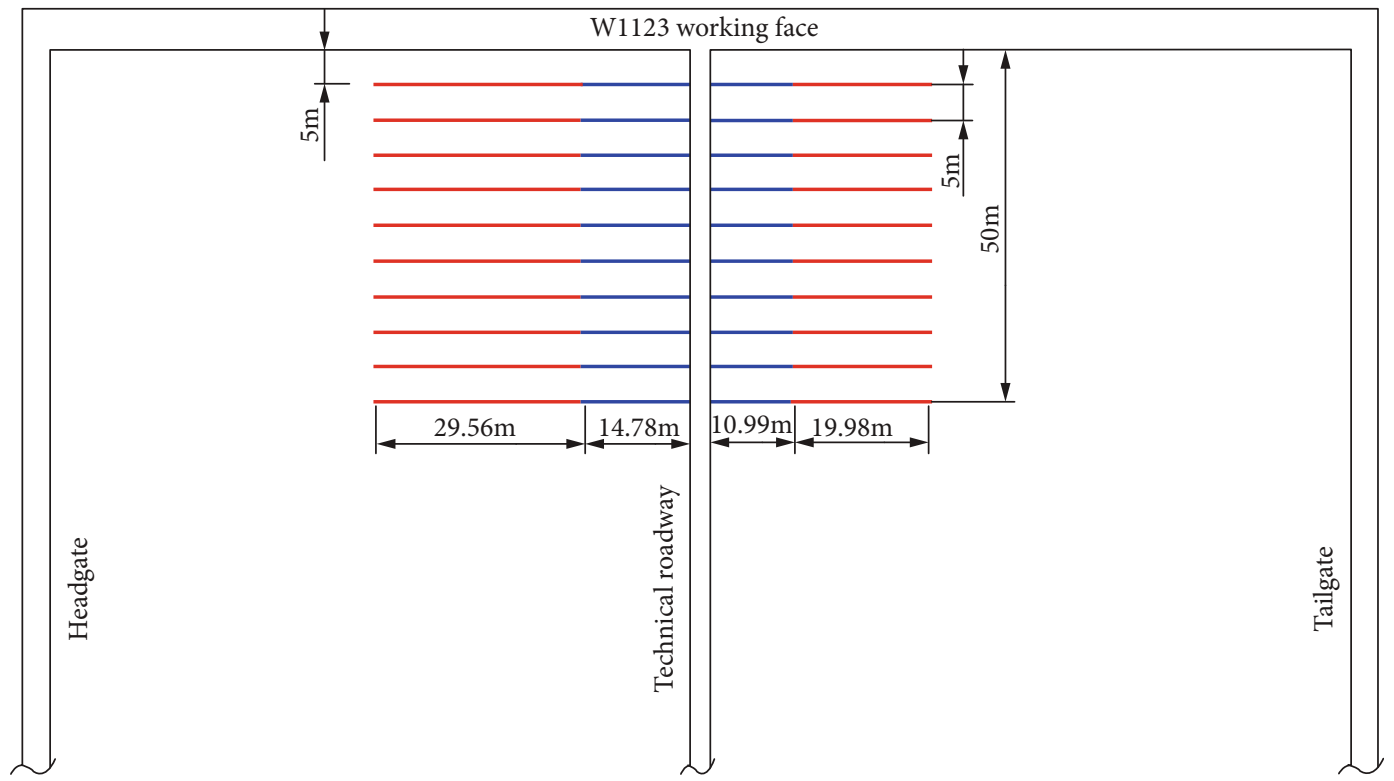

(a)

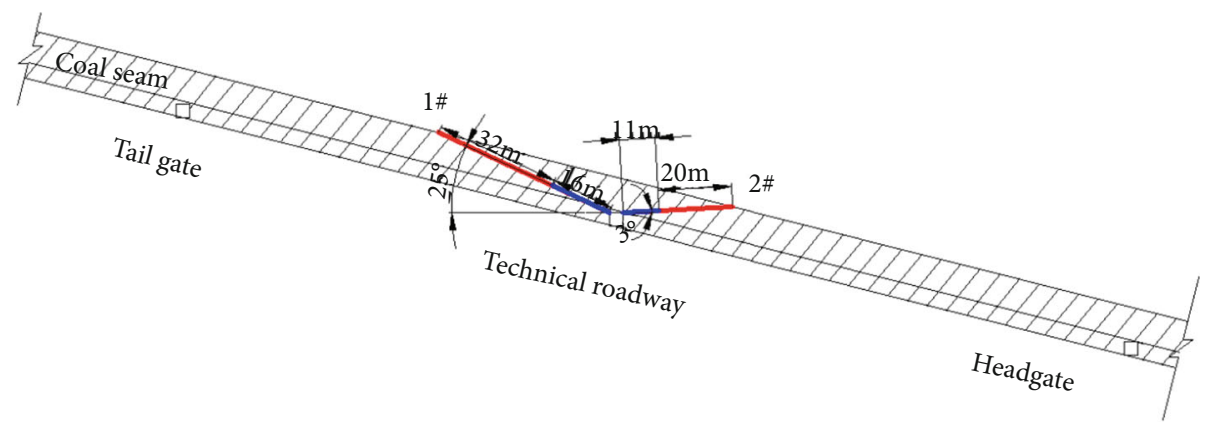

(b)

Figure 18: Blasthole layout scheme. (a) Plane diagram. (b) Section diagram.

TABLE 6: parameters of deep-hole blasting, hole drilling, and filling explosive.

\begin{tabular}{lccccccc}
\hline $\begin{array}{l}\text { Hole } \\
\text { number }\end{array}$ & $\begin{array}{c}\text { Borehole } \\
\text { length }(\mathrm{m})\end{array}$ & $\begin{array}{c}\text { Horizontal } \\
\text { angle }\left(^{\circ}\right)\end{array}$ & $\begin{array}{c}\text { Elevation } \\
\text { angle }\left(^{\circ}\right)\end{array}$ & $\begin{array}{c}\text { Borehole diameter } \\
(\mathrm{mm})\end{array}$ & $\begin{array}{c}\text { Filling explosive } \\
\text { length }(\mathrm{m})\end{array}$ & $\begin{array}{c}\text { Plugging } \\
\text { length }(\mathrm{m})\end{array}$ & $\begin{array}{c}\text { Explosive filling } \\
\text { weight }(\mathrm{kg})\end{array}$ \\
\hline 1 & 48 & -90 & 25 & 94 & 32 & 16 & 160 \\
2 & 31 & 90 & 3 & 94 & 20 & 11 & 100 \\
\hline
\end{tabular}

Note: the horizontal angle is the angle between the drilling direction and the center line of the roadway. Elevation angle is the angle between the drilling direction and the horizontal line of the roadway.

human intervention. Avoid a sudden release of a large amount of elastic power at one time. Precracking the end is actually a method of cutting the roof, that is, allowing the roof to collapse along the designed position to avoid forming a roof hinged structure to form a high stress area inside the coal pillar

(ii) The coal body engineering: blasting of the coal body can not only improve the resource recovery rate of top coal caving but also cause many cracks in the coal body, and large diameter drilling can cause free space in the coal body. To guide the stress release in the coal body, the above two measures are to actively release the elastic energy in the coal body to avoid the accumulation of elastic energy

In the effect detection method, the microseismic monitoring system, acoustic emission monitoring system, and electromagnetic emission monitoring system can process the vibration signal, acoustic signal, and electromagnetic radiation signal to reflect the degree of deformation, fracture, and energy release in the coal and rock mass [25-30]. The drilling television system can directly reflect the effect of roof cutting and precracking after blasting $[31,32]$. Through these kinds of methods, the effect of treatment is evaluated, and the parameters of treatment measures in the later stage are provided. 


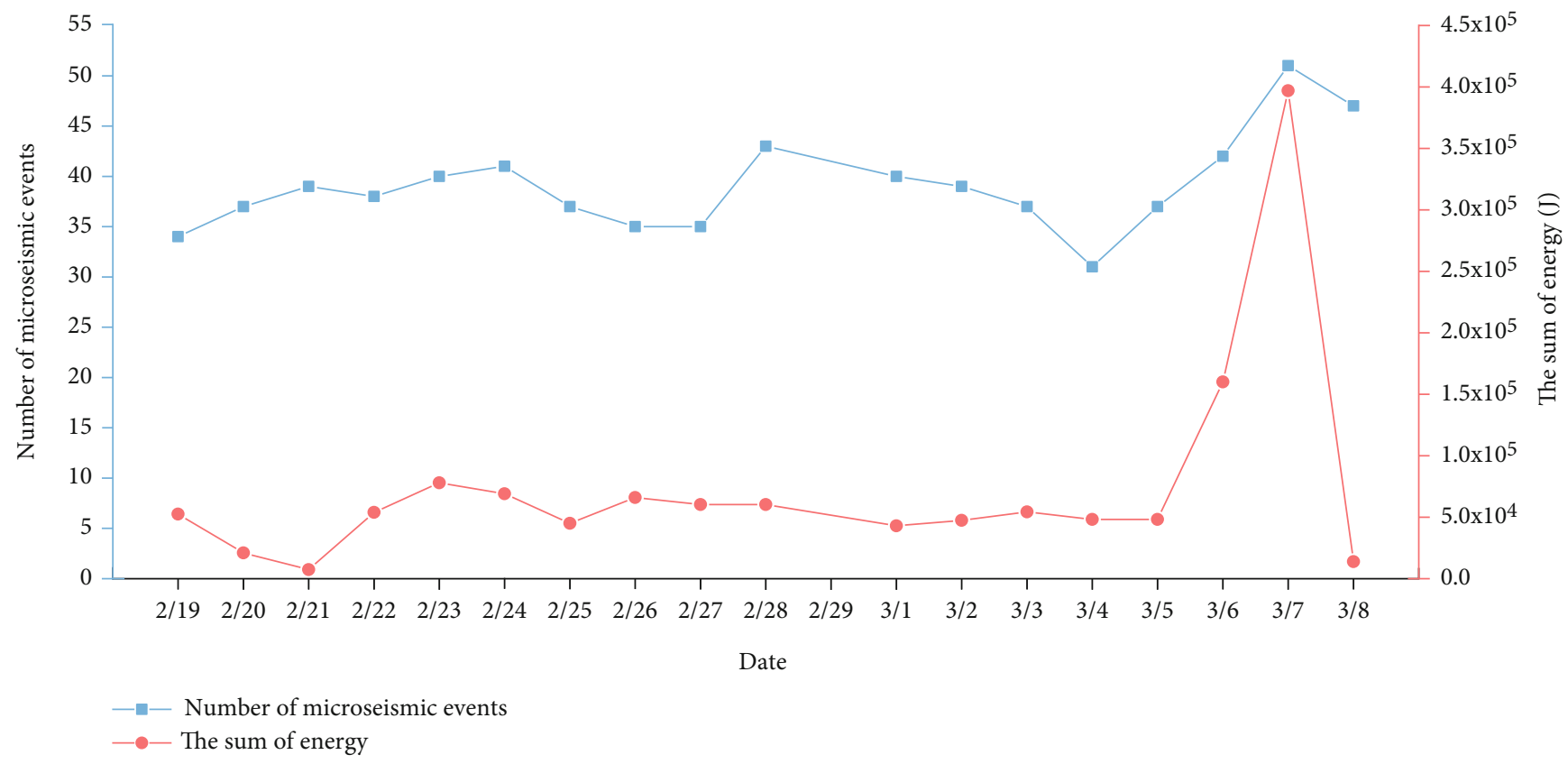

FIGURE 19: Characteristics of microseismic events after pressure relief measures.

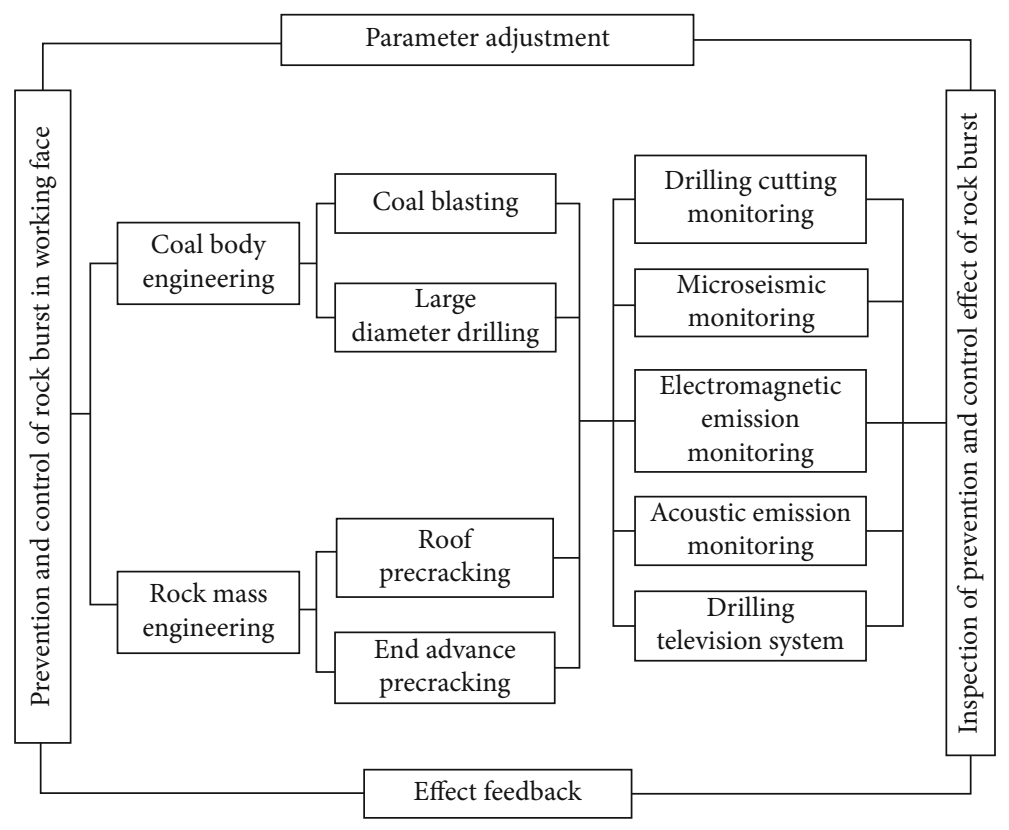

Figure 20: Prevention and control measures of rock burst.

\section{Conclusion}

(1) The numerical simulation shows that the high stress concentration area has appeared on both sides of the coal pillar when the W1123 working face does not start mining. With the advance of the working face, the high stress concentration area forms an Xshaped overlap. The position of the obvious increase of the stress of the coal pillar in the lower part of the solid coal is ahead of the advancing position of the working face, and the position of the obvious increase of the stress of the lower coal pillar in the gob lags behind the advancing position of the working face

(2) The result of a similar material simulation experiment shows that it is easy to form roof hinged structure under the condition of super thick and hard roof, and the existence of structure greatly increases the stress value in the interior of coal pillar

(3) The pillar rock burst in the W1123 working face is the result of both static load and dynamic load, but the fuse causing the rock burst is the energy release 
caused by the breaking of the key strata. The energy released by the key strata breaks the stress balance limit in the coal pillar and results in the occurrence of rock burst

(4) Considering the various factors of induced rock burst, the source of induced rock burst will be dealt with the strata to avoid the accumulation of elastic properties of roof strata and deal with coal seams to avoid the accumulation of elastic properties of coal seams. The effect of treatment measures is evaluated, and the parameters of treatment measures are adjusted by using microseismic monitoring, acoustic emission monitoring, and other equipment to form a feedback regulation mode

\section{Data Availability}

The test data used to support the findings of this study are included within the article. Readers can obtain data supporting the research results from the test data table in the paper.

\section{Disclosure}

I would like to declare on behalf of my coauthors that the work described was original research that has not been published previously and not under consideration for publication elsewhere, in whole or in part.

\section{Conflicts of Interest}

No conflict of interest exits in the submission of this manuscript

\section{Authors' Contributions}

The manuscript is approved by all authors for publication. All the authors listed have approved the manuscript that is enclosed.

\section{Acknowledgments}

The study has been supported by the Key Research and Development Program of Shaanxi Province (2018ZDXMSF-018), the National Natural Science Foundation of China (No. 51904227), the Natural Science Foundation of Shaanxi Province (No. 2018JQ5194), the China Postdoctoral Science Foundation (No. 2017M623328XB), the Shaanxi Key Science and Technology Innovation Team Project (No. 2018TD038), the Hunan Province Engineering Research Center of Radioactive Control Technology in Uranium Mining and Metallurgy \& Hunan Province Engineering Technology Research Center of Uranium Tailings Treatment Technology (No. 2018YKZX2001), and the Opening Project of Cooperative Innovation Center for Nuclear Fuel Cycle Technology and Equipment, University of South China (No. 2019KFY25). Supports from these agencies are gratefully acknowledged.

\section{References}

[1] Y. D. Jiang, Y. S. Pan, F. X. Jiang, L. M. Dou, and Y. Ju, "State of the art review on mechanism and prevention of coal bumps in China," Journal of China Coal Society, vol. 39, no. 2, pp. 205213, 2014.

[2] Y. S. Pan, Z. H. Li, and M. T. Zhang, "Distribution type, mechanism and prevention of rockburst in China," Chinese Journal of Rock Mechanics and Engineering, vol. 22, no. 11, pp. 18441851, 2003.

[3] D. Y. Zou and F. X. Jiang, "Research of energy storing and gestation mechanism and forecasting of rockburst in the coal and rock mass," Journal of China Coal Society, vol. 29, no. 2, pp. 159-163, 2004.

[4] Z. Khademian and U. Ozbay, "Modeling violent rock failures in tunneling and shaft boring based on energy balance calculations," Tunnelling and Underground Space Technology, vol. 90, pp. 62-75, 2019.

[5] P. F. Shan, X. P. Lai, and F. Cui, "Energy dissipation properties and mechanisms of fractured coal-rock mass failure under mining condition," Journal of Mining and Safety Engineering, vol. 35, no. 4, pp. 834-842, 2018.

[6] F. Gong, J. Yan, X. Li, and S. Luo, "A peak-strength strain energy storage index for rock burst proneness of rock materials," International Journal of Rock Mechanics and Mining Sciences, vol. 117, pp. 76-89, 2019.

[7] K. Du, M. Tao, X. B. Li, and J. Zhou, "Experimental study of slabbing and rockburst induced by true-triaxial unloading and local dynamic disturbance," Rock Mechanics and Rock Engineering, vol. 49, no. 9, pp. 3437-3453, 2016.

[8] S. Wang, L. Huang, and X. Li, "Analysis of rockburst triggered by hard rock fragmentation using a conical pick under high uniaxial stress," Tunnelling and Underground Space Technology, vol. 96, article 103195, 2020.

[9] K. Du, C. Yang, R. Su, M. Tao, and S. Wang, "Failure properties of cubic granite, marble, and sandstone specimens under true triaxial stress," International Journal of Rock Mechanics and Mining Sciences, vol. 130, article 104309, 2020.

[10] X. P. Lai, H. Sun, and M. Cai, "Mechanism of dynamic hazards due to coal and rock mass instability in extremely steep coal seams with the deepening mining," Journal of xi'an university of science and technology, vol. 37, no. 3, pp. 305-311, 2017.

[11] J. T. Cao, X. P. Lai, F. Cui, and P. F. Shan, "Characteristics on dynamical deformation and instability of coal and rock mass in mining disturbed zone (MDZ) of steeply dipping heavy thick coal seams mining," Journal of xi'an university of science and technology, vol. 35, no. 4, pp. 394-402, 2015.

[12] J. F. Pan, Y. Ning, D. B. Mao, H. Lan, and T. T. Du, “Theory of rockburst start-up during coal mining," Chinese Journal of Rock Mechanics and Engineering, vol. 31, no. 3, pp. 586-596, 2012.

[13] S.-y. Gong, J. Li, F. Ju, L.-m. Dou, J. He, and X.-y. Tian, "Passive seismic tomography for rockburst risk identification based on adaptive-grid method," Tunnelling and Underground Space Technology, vol. 86, pp. 198-208, 2019.

[14] G. A. Zhu, L. M. Dou, C. B. Wang, Z. W. Ding, Z. J. Feng, and F. Xue, "Experimental study of rock burst in coal samples under overstress and true-triaxial unloading through passive velocity tomography," Safety Science, vol. 117, pp. 388-403, 2019. 
[15] J. Dai, P. Shan, and Q. Zhou, "Study on intelligent identification method of coal pillar stability in fully mechanized caving face of thick coal seam,” Energies, vol. 13, no. 2, p. 305, 2020.

[16] Z. Y. Wang, X. P. Lai, and X. M. Liu, "Construction and application of the GRNN model of coal section pillar width prediction in fully mechanized face," Journal of xi'an university of science and technology, vol. 39, no. 2, pp. 209-216, 2019.

[17] X.-p. Lai, P.-f. Shan, M.-f. Cai, F.-h. Ren, and W.-h. Tan, "Comprehensive evaluation of high-steep slope stability and optimal high-steep slope design by 3D physical modeling," International Journal of Minerals Metallurgy and Materials, vol. 22, no. 1, pp. 1-11, 2015.

[18] X. P. Lai, Y. P. Wu, and J. T. Cao, "Experiment on rock-mass deformation of large scale 3D-simulation in complex environment," Journal of China Coal Society, vol. 35, no. 1, pp. 31-36, 2010.

[19] D. Bakun-Mazor, Y. H. Hatzor, and W. S. Dershowitz, "Modeling mechanical layering effects on stability of underground openings in jointed sedimentary rocks," International Journal of Rock Mechanics and Mining Sciences, vol. 46, no. 2, pp. 262-271, 2009.

[20] M. G. Qian, P. W. Shi, and J. L. Xu, Ground pressure and strata control, China University of Mining and Technology Press, Xuzhou, 2003.

[21] W. L. Wang, Books for Teaching in Colleges and Universities, Drilling and Blasting, Coal Industry Press, Beijing, 1984.

[22] Z. Ding, J. Jia, X. Li, J. Li, Y. Li, and J. Liao, "Experimental study and application of medium-length hole blasting technique in coal-rock roadway," Energy Science and Engineering, vol. 8, no. 5, pp. 1554-1566, 2020.

[23] D. J. Yan and C. H. Sun, "Discussion on method of calculating of radius of blast cracked zone in rock mass," Blasting, vol. 27, no. 2, pp. 29-31, 2010.

[24] Y. Zhang, S. Cao, N. Zhang, and C. Zhao, “The application of short-wall block backfill mining to preserve surface water resources in northwest China," Journal of Cleaner Production, vol. 261, article 121232, 2020.

[25] F. Cui, Y. B. Yang, X. P. Lai, and J. T. Cao, "Similar material simulation experimental study on rockbursts induced by key stratum breaking based on microseismic monitoring," Chinese Journal of Rock Mechanics and Engineering, vol. 38, no. 4, pp. 803-814, 2019.

[26] P. Shan, X. Lai, and X. Liu, "Correlational analytical characterization of energy dissipation-liberation and acoustic emission during coal and rock fracture inducing by underground coal excavation," Energies, vol. 12, no. 12, p. 2382, 2019.

[27] L. M. Dou, X. Q. He, E. Y. Wang, and D. Z. Gu, "Electromagnetic emissions in rock and coal burst failures," Journal of Tsinghua University (Science and Technology), vol. 41, no. 12, pp. 86-88, 2001.

[28] C. A. Tang and Y. F. Yang, "Crack branching mechanism of rock-like quasi-brittle materials under dynamic stress," Journal of Central South University, vol. 19, no. 11, pp. 32733284, 2012.

[29] H. Yan, J. Zhang, N. Zhou, and M. Li, “Application of hybrid artificial intelligence model to predict coal strength alteration during $\mathrm{CO} 2$ geological sequestration in coal seams," Science of the Total Environment, vol. 711, p. 135029, 2020.
[30] Z. Ding, J. Jia, and R. Feng, "Effect of the vertical stress onCO2flow behavior and permeability variation in coalbed methane reservoirs," Energy Science and Engineering, vol. 7, no. 5, pp. 1937-1947, 2019.

[31] Y. Zhang, S. Cao, S. Guo, T. Wan, and J. Wang, "Mechanisms of the development of water-conducting fracture zone in overlying strata during shortwall block backfill mining: a case study in Northwestern China," Environmental Earth Sciences, vol. 77, no. 14, 2018.

[32] Q. Liu, J. Chai, S. Chen, D. Zhang, Q. Yuan, and S. Wang, "Monitoring and correction of the stress in an anchor bolt based on Pulse Pre-Pumped Brillouin Optical Time Domain Analysis," Energy Science \& Engineering, vol. 8, no. 6, pp. 2011-2023, 2020. 